\title{
THE GENESIS OF ARCHITECTURAL SPACE ${ }^{\#}$
}

\author{
GYULA J. HAJNÓCZI \\ Correspondent member of the Hungarian Academy of Sciences, architect, architectural historian, \\ archaeologist, professor (Baja, 1920 - Budapest, 1996). \\ Department of History of Architecture and Monument Preservation, \\ BME K II. 82, Müegyetem rkp. 3, H-1111 Budapest, Hungary.
}

The first version of this paper was written in Hungarian as the final summarizing study of the OTKA research entitled "Building and Settlement Characterology". ${ }^{1}$ The study entitled "The Genesis of the Architectural Space" is a concise summary of Gyula Hajnóczi's spatial theory research that offers a thorough overview also for less experienced researchers in architectural theory. This valuable writing - although published in Hungarian as a series of journal articles or in copied version - is hardly known to the architectural profession. ${ }^{2}$ The English version published here helps to make Hajnóczi's space theory more widely available to professional circles, and on the other hand, it can also serve as an important reading for architecture students studying in English. The translation was made according to a later manuscript version of the OTKA final study intended for print, with the support of the copyright holder.

Keywords: theory of architecture, space theory, space creation

When constructing a house, man erects a building, and at the same time creates an artificial space, both exterior and interior. He is not alone in nature with this knowledge of construction, as in the fauna several species find protection, store their food, reproduce, etc. within their own self-made frameworks. What distinguishes the activity of a builder human from the instinctive construction of animals is that he not only creates a shelter for himself following his instincts, but also builds a home for his gods with faith and consciousness. Making use of the double meaning of the Latin word - aedes - which denotes both a dwelling house and a church, it can be simply and aptly illustrated that architecture is able to satisfy not only the material but also the spiritual needs of people. Human is a homo aedificator.

\footnotetext{
\# The article was translated by Gaschler-Gyeviki, Nóra. This publication was supported by the National Cultural Fund of Hungary (NKA) under Grant Number 101108/547.

${ }^{1}$ OTKA (Hungarian National Research Fund) Grant No. 283 "Building and Settlement Characterology", 1988-1991; Lead researcher: Gyula Hajnóczi.

${ }^{2}$ It was not published in an architectural journal, only in the periodical Iskolakultúra (http://www.iskolakultura.hu/index.php/iskolakultura/ accessed 16 December 2020), which publishes research articles related to education: Hajnóczi, J. Gyula: Az építészeti tér genezise (Part I.). Iskolakultúra 2 (1992) 22. 2-10. http://www. iskolakultura.hu/index.php/iskolakultura/article/view/28788; Hajnóczi, J. Gyula: Az építészeti tér genezise (Part II.). Az érzékszervek szerepe a térérzékelésben. Iskolakultúra 2 (1992) 23-24. 10-21. http://www.iskolakultura.hu/index.php/iskolakultura/article/view/28809; Hajnóczi, J. Gyula: Az építészeti tér genezise (Part III.). Az építészeti tér megteremtése. Iskolakultúra 3 (1993) 1. 20-33. http://www.iskolakultura.hu/index.php/iskolakultura/article/view/28846; Hajnóczi, J. Gyula: Az építészeti tér genezise (Part IV.). Iskolakultúra 3 (1993) 5. 35-43. http://www.iskolakultura.hu/index.php/iskolakultura/article/view/28918
} 


\section{HOMO AEDIFICATOR}

The house is made by the man himself. He cuts wood, forms, and burns brick, carves stone, etc. He then begins various manipulations to put the materials together and then starts thinking to come up with the most suitable structure possible. In a building, the manual work of a man is as "inherent" as his knowledge, even when assembling the simplest hut.

But there is much more in a man-made work. He hides his own physiognomy into his creation: that is, he copies directly and indirectly the proportions of the human body, sometimes even its forms. Man marks certain details of the building with the names of his own structure. He consciously/unconsciously builds something like the former dwellings of his distant past. He forms the framework of his life in accordance with his habits and various actions, which thus becomes a mimesis of his scope of activity. Man, therefore, anthropomorphizes his built environment both "statically" and "dynamically".

However, the built environment itself is embedded in some kind of environment: first in a larger built context, then into nature, or in an even wider sense: into the world. Man chooses and uses the conditions of the environment at the level of the living conditions, knowledge and culture of each specific period, and he inserts a building into this environment that appears to sprout from there. However, not only the spirit of the place, the genius loci, but also the spirit of the age, the genius aetatis, permeates the man-made work, so that it will eventually become a color-changing mirror of the current worldview. Involuntarily, each building works this way, but it is especially true in a spectacular way for the houses that can be measured and characterized by the expressive and evaluative norms of art. And architecture was given not just any rank in the hierarchy of the arts, for there were times when it was considered the mother or the genius of the fine arts. And the fact that this rank was later withdrawn from architecture, and its nature of art was questioned at all, does not change the point.

Thus, the built environment is not simply a physical environment, but an objectified form of human behavior, a summary of life moments realized by the specific means of architecture. In which the Self and the community, the past and the present are summed up. If all this is true, then the question rightly arises: how the many things that dead material absorbed into itself when it came to life as a building were created.

Some answer this question by incorporating architecture into the line of human achievements, and say: anyone can lay a plank over the stream, but very few can draw the plans of a cable-stayed bridge and build it accordingly; a simple machine, a hoist, a shadoof, or a wheeled well can be used and even constructed by anyone, while a steam engine or an internal combustion engine - a locomotive, a car - can only be designed by the "chosen ones"; chamomile flowers or other herbs can be collected by everyone in the meadow and forest, however, a Koch, a Semmelweis, a Pasteur is not born every day; to sit on a horse, to be a messenger courier, to fly a carrier pigeon are relatively simple ways of long-distance news exchange, but com- 
munication by Morse signals, telephone, radio, TV is by no means an easy solution. But is this also true of architecture? Anyone can build a simple shelter, a modest house of prayer, but of course not a skyscraper, a chapel in Ronchamp - says the quick reckoning.

However, the answer is only true in the narrower sense. Because man is not only a tool-making animal, but also a housebuilder, so it is part of his self's essence to extend the framework of his fallibility and vulnerability, in order to protect him. Everyone can build - just as eat, sleep, and so on - because he was forced to do so. Because God drove him out of the Garden of Eden, where he could live naked and not only had to get his food, but he had to find a shadow with blood, sweat and tears, he had to raise hut and shelter in his exile. Man is a - homo aedificator.

History can be called to bear witness. Seeing the greatness of architectural works from some thousand years ago, human culture has hardly any such accomplishments that earn even the admiration of modern man and, at the same time, his amazed disbelief. Many times, we just guess how these works came into being. It is no coincidence that fantastic theories have sprung up about their seemingly mysterious origins. But looking back even further, into the culture of the prehistoric age (and natural peoples), we find that their tools: the fire-strikers, utensils, bow drills, etc. are just curiosities for us, but their houses and villages mean more than that. We look at the rationality of the structure of the houses, the ingenuity of the construction method, the beauty of the buildings' formation as equivalent to some creation of today. We understand the practicality of the siting order of their villages, but also the way the rules of social life influenced the structural arrangement of settlements and houses. Thus, in a very ancient stage of man's construction activity, there are moments that have not yet become obsolete to this day. According to our values and our axiology today, it seems that certain areas of human culture have not changed - if you like: have not evolved - in parallel, the progress of some of them is judged to be slower and the other to be faster. And architecture is one of those areas, along with the healing knowledge of humanity, that developed relatively early to a level that its works became almost incomparable with other (especially material) manifestations of culture, and it has kept this distance of advantage for a long time. All this can only be interpreted by assuming that some fundamental behavior of man was embodied in architecture.

\section{HOMO ARCHITECTUS}

The almost instinctive behavior of construction has encouraged and led people to bring to life a range of buildings of different ranks and values according to their own abilities, circumstances and needs. At the same time, a specific type of the homo aedificators emerged, who began to view and to practice this activity differently than thousands of his peers (he is the one who already participated in the creation of the aforementioned generous works). The first such "eccentric" - who was also known by name and lived around $2600 \mathrm{BC}$ - was called Imhotep. He was an Egyptian chan- 
cellor, i.e. the "prime minister" to the Pharaoh. As an eternal resting place, he built a tomb city for his emperor which, without any precedents, has become almost the most magical work in the country, both technically and artistically. The inventive Imhotep was later revered as a demigod, even the discovery of the science of medicine and healing was attributed to him. This is how the homo aedificator, the explorer and the inventor, became a homo architectus.

$\mathrm{He}$, and, of course, many like-minded people around him, began to consciously gather and systematize the past experiences in this profession, and gradually learned to shape the wishes of either individuals or communities into buildings. In addition to the simple practicality of construction, these people have become understanders of intellectual endeavors and successfully incorporated these aspirations into the dead material. They were quite similar to the groups being "crystallized" in other areas of culture - today we say: the intellectual elite - all of which were active in their profession to gradually increase their knowledge in service of the public interest. Each group had to deal with disinterest and incomprehension, traditions and bigotry and other obstacles, although they wanted the best of their faith. According to the differences in circumstances and needs, sooner or later the flowers of their efforts may have bloomed, and the fruits were ripe. The greats who wrote the epoch-making pages of the history of science and culture were chosen. Among them, however, perhaps no one tolerated and suffered as much as the architect, and no one's "science" had as many twists and turns as his one: i.e. architecture.

Homo architectus began his career as a demigod, then was considered a mere craftsman for a long time, he was accepted and sometimes even halos were drawn around his head and his work, finally, these days he seems to have finished and reached the twilight of his life. All this seems to be justified by the internal and external history of architecture. Architecture itself is so human, and it belongs so much to our lives, that its fate is like the human fate of all time.

The life of a building is mortal, like that of man. True, it has a much longer life, since the house built by a family for itself can serve as a home for the second, or next family, even for generations. If the house is "sick", it will be cured, and continuously used until it is permanently outdated, and a new one must be built. As long as human life pulsates within the walls, the life of the house will not be interrupted. The difference between a building's and a person's lifespan gives one of the beauties of architecture, and much more than that. It provides what an old family house means to us, what an old town can offer: the illusion of the continuity of life, the feeling of security that we are not alone, naked and vulnerable in the world. This is why a new building, a new housing estate, is "soulless" even though it is modern, hygienic and attractive, because it has less to tell us about life than its old counterparts.

But the same difference is the fatal legacy of architecture. Eras change each other and erase what could still be used. In the best case, the house is converted, or the remains of the old building are used as construction materials, so some part of it - through a kind of transcendence - still lives on. What is happening today is that the desire of preserving cultural continuity is confronted with meeting the demands of 
civilization and other aspects of our modern life, especially transport, therefore old and respected buildings and neighborhoods are condemned to demolition. One or the other of them may survive in its original place but will live on in an isolated alienation. Others are saved and relocated to open-air museums and people visit them almost with piety to admire the surviving heralds of past lives.

And all the above is nothing special, for it is a natural corollary of the passing of life. Less so self-evident is the multitude of moments arising from the dialectic of architecture. The most characteristic of them is the resentment with which each period views the image and style of the immediately preceding architecture. Seemingly, this behavior consciously began in the Renaissance, as if it were a hallmark of impulsive Western European culture. What we admire today, e.g. in Gothic style, was considered a barbaric degeneration at the dawn of the Pre-Modern age. First Gothic was a nickname, then it has become an accepted style marker, as has the Baroque, which is named after the irregular, flawed pearl. The second large-scale denial had to be suffered by the Baroque and the Rococo, when the shining altars were thrown out from the churches, because the whole design was perceived as sickly lush and incomprehensibly prolific. In the judgment of Eclecticism, the dislike then waned to the point of seeking to destroy the style. Partly Art Nouveau (this style also got its pejorative connotation, i.e. being ugly), and completely Modernism wished for the demise of Eclecticism.

However, this dialectic of successive periods dissolves into the gradual acceptance of older architecture. So, architecture itself seems to be struggling with generational problems: grandparents are more tolerant of their grandchildren than of their children, and vice versa. It is hardly debatable that this phenomenon is also related to fashion. Most importantly, however, it is now about the man-made world that homo architectus created. Even if he was exposed to the arbitrariness of the potentates who ordered the work. However, in order to realize his ideas, he almost always had to fight "upwards", because everything came from there: the assignment of tasks, and also recognition or condemnation. For four hundred years of the modern age, the architect has played a decisive role in shaping the architectural culture, which, as an integral part of art, has flourished and changed its color according to the complex laws of art.

Modernists then attempted to exclude architecture out of this sphere, proclaiming that it did not belong to the arts. The various human actions have been interpreted as mere technological processes, thus "customized" and "appropriate" buildings were erected accordingly. Architecture was simplified both in content and form, almost being self-standardized, its spread took on a global dimension, and became supranational.

As an interluder, it became a propaganda tool for power ideologies. The over-technicalized revolution originally intended to be an internationalist movement then culminated in a neo-humanist and neo-regionalist counter-revolution. Such a cavalcade of ideas and aspirations has distorted the moods of a wide variety of disciplines, and the debates of architecture were joined by shrinks, social scientists, philosophers, and many other specialists and protectors of human life. Not to mention the contra- 
dictions within the profession - between architects and constructors. Homo architectus was thus forced to fight "laterally" as well. Modernism, considered an orthodox approach, was blamed not only for baldness, but also for being "overfunctional". At the same time, opponents also complained that Modernism could not meet people's individual needs, in response to which they started to experiment with flexibility. Eventually, the architect, being excluded from his former "aristocratic" position, was forced to be compromised "downwards" as well.

And if we add to all this that in the scheme system of sciences adopted by UNESCO, at least half a hundred other words can and should be lined up next to Architecture in order to practice and interpret the profession of architecture, the presumption is confirmed: to build is the basic and universal need for human existence. All people are homo aedificators, just like the homo architectus.

\section{THE THREE FACES OF SPACE}

The universality of man's need and skill for construction can only be justified if we find recognizable traces of the human hand in a building that has come to life from dead material. And it is just a simple thing, as everyone can easily understand that the doorway needs to be shaped so that the house and the room can be entered with the head raised; the steps must be adapted to the feet and steps of man; a column has a base, a shaft, and a capital, it is not advisable to swap the scenes of human metabolism - the dining room and the toilet - in the house; a table, a chair, a bed should be adapted to the dimensions of a human body ready or willing to lay down, sit, relax, etc. But how can we cope with the challenge of showing the human aspects of something disembodied, i.e. the architectural space?

Well, to give the right answer, we have to start from the man himself. All the physical-mental-intellectual factors should be taken into account which determine a person's perception of space. Along with these, we need to discover what imaginations help man to experience, interpret and use space and finally: what temporary - ephemeral - spaces man is able to create, almost toolless.

It is then necessary to determine the relationship between man and objects. An unfurnished room, a street, or an urban space without "street furniture" is a rare phenomenon. Therefore, people surround themselves with furniture that enable and make life easier. Equipment and installation create an almost separate, independent spatial world with which man is in direct contact, arranging these useful or pleasing objects one way or another, moving and living between them. Secondly, by revealing the characteristics of the usually changeable - mobile - space defined by the furniture, the relationship between man and space can be experienced. Nothing justifies the existence of this group of phenomena more than the fact that no permanent and lasting built environment is necessary for its development. It is enough to think of a garden party, where tables, benches, chairs are placed on the lawn in an unsettled way, and of acute spatial situations thus formed. 
The third is the "built" space, i.e. the approach to the relationship between man and architectural space in the strict sense. The timeless - chronic - architectural space is the scene of civilized - or civil-cultured - human life, which he has created, experiences, understands and uses himself. Ad absurdum: it is also a mobile space, as it can be destroyed, replaced by another one, but its lifespan is usually longer than that of humans. Due to their relative permanence, these "built" spaces can be evaluated almost on their own, their types can be systematized in some way, and their characteristics can be determined. And not only one time and in the same way, as these spaces can get in the possession of different people, different eras. The multitude of books on the history and theory of architecture deals almost exclusively with these spaces created within a timeless framework.

However, it is hardly debatable that only the clarification of the essence of the three space types: ephemeral, mobile, and chronic space promises success. And it is even clearer that lining up the variations of real situations created by the overlap of these spatial types can lead to a complex interpretation of man-made space. In fact, the three types of spatiality always overlap, their separate discussion is only explained by didactic reasons, and by the fact that the various literature statements dealing with space are easier to review.

It is a well-known and repeated paradox that the recognition of architectural theory and art history saying that the distinctive feature of architecture is the creation of space dates back only a hundred years. However, this definition set in motion a complex process in which the previously relatively closed world of architecture became open to criticism of various disciplines. The experts and scientists of ethology, anthropology, physiology, psychology, sociology, environmental protection, communication, etc. began to give advice to the homo architects, the "ordained priests" of the universal community of homo aedificators.

However, the uncertainty created by the bulk set of information can only be dispelled if architects themselves simplified the interpretation of architecture, filtering out real values from the increased body of knowledge.

The task, then, is to define the space that gives the essence of architecture with the presumed genesis, and success can only be hoped if we rethink what is already known and measure newly invented ideas.

\section{GETTING FAMILIAR WITH SPACE - THE SPACE CREATED}

The first habitat of man is the womb. This flexible envelope that changes its shape is the first "all-comfort" apartment, a "rented" room for us. We can trace back the life of the embryo to the time before conception, when two people have already carried in their genes many of the determining factors of the fate of the born "one", and his/ her future relationship to the world. The embryo may need to share its home, two, sometimes even more babies can fit in it, maybe a boy and a girl together. The strange thing about nature is that human life can start outside of this envelope, but cannot develop further, only if an artificial space is created for it. 
So, in prenatal time, real drama takes place in these few cubic decimeters of space. We do not need to have precise anatomical and biological knowledge to know that nature has placed another medium between the envelope and the baby, that the embryo is fed by the mother's body through the umbilical cord, and the tiny human being can move and be moved indirectly together with his/her mother. The small creature takes on a characteristic posture that fits smoothly with his forced residence and that accompanies him in his future worldly life. He grows and experiences the rhythm of the mother's body. It can be reasonably assumed that all these include motivations that will determine the human relationship with the environment. After all, such thoughts can be associated to this situation as: protection-need, reservationrelocation, looseness in attachment, individuality-social existence, etc.

The fact that the womb is the first shell of our lives encourages further reflection, which requires a small intellectual bypass. A specific phenomenon accompanies the results of human culture: there are two poles that contradict but at the same time complement each other. The ancient philosophers, more precisely: Pythagoras and his circle, "discovered" that there are numbers, but there must also be some kind of medium in which they fit, because without this medium they would be blurred. To put it simply, we can say that we have a tangible element (the number) and an intangible one (space between the numbers). There are two types of vowels in the predetermined mode of communication and human information exchange, i.e. in speech: the consonant and the vowel. So, human speech also has a "cumbersome" element (the consonant), and an "airy" element (the vowel) that is easier to pronounce. Similarly, in the man-made environment there is an object-like element (the walls) and a spatial one (the space between the walls), and these two create the building.

This controversial relationship between object and space, which at the same time resolves their contradictions, leads to the conclusion that the object is the masculine, and the spatial quality is the feminine. Consequently, the essence of space is inherently something feminine, since it is the receiving medium that ensures existence.

The concept of space as a feminine principle is simply based on formal similarity. However, this can be supplemented by behavioral observations as well. In a matriarchy, the woman is the stationary sex, the man comes and goes, according to his duties. The same is true of the natural tribes where women cultivate the land and men collect food or hunt in the woods and fields. A woman is not prone to sudden changes, she is in charge of permanence, preservation, retention and continuation of life. The main character who creates the home of the family's "nest" is the "housewife", who, if something unpleasant happens, rearranges the furniture, and changes her immediate environment just to reduce stress. It is not known whether statistics have been prepared on the gender distribution among talented interior designers, but surely a lot of them are women. But she does not even have to be a professional decorator: she instinctively does that. Just like moving and displacement is the instinct of men; and everything that can be said about the man-made space emerges out of these two habits, from this inherent "statics-dynamics". 
When the newborn leaves his "rented room" through that particular hole (which is itself a space, just think of the pictorial analogy of the locksmith jargon "female screw"), he/she gets from the small pail into a big bucket: the outside world. But regardless of whether the baby is a boy or a girl, he/she will be a masculine element because he/she has a body, a "mass" - if the previous illustrative parables deserve credit. The little child is a six-sided creature, even if his/her body is made up of organically shaped elements: he/she has soles, a head top, a right and a left side, and a front and a back part. In addition, God gave him two arms, two legs, a lap, etc. - all the "tools" to separate small spaces from infinite space and to "dress" himself with these spaces when spreading his arms, shaking his legs, or curling. His senses are already functioning to some extent, but the information provided by them are preceded by the fact that his mere corporeality creates some kind of space, both on its own but also in relation to others, e.g. when laying on his mother's breast.

With these seemingly insignificant gestures, man can perceive exactly what he is doing, and then gradually develops his skills in it. Man receives the "first space" as a gift from the Creator, but the second is created by himself.

\section{COORDINATES OF HUMAN SPACE}

However, there is still a long way to go to the 'actual' creation of space - from infinite spatial quality to finite delimitation. As Moses wrote, Yahweh-Elohim created the world in six days. Well, man creates his own world fivefold: through his five senses. However, the latter number is inaccurate because the human body has several important properties that are not included in the list of commonly cited informative organs and which must be taken into account in man's relation to space. Such is the mere fact that a person has a vertical spine, which determines his way of standing and moving, or that the muscular system of the human body is also a sensing organ, finally, that the data transmitted by the senses are processed in a central place, i.e. in the head or brain located at the top of the human figure.

Man is the only high-order "faunic" creature in nature who lives with a definite and almost exclusively vertical posture. Of course, he can crawl, climb on all fours, jump squats, etc., but these forms of posture and movement are not specific to the adult: they are only compulsive or playful, if you like, atavistic situations. The defining and characteristic "basic way" of moving is to walk on both feet. Which forces this vulnerable creature into a rather shaky position, who is four-legged when being a baby, two-legged as an adult, and three-legged in the twilight of his life - walking with the help of a stick - according to the solution of the ancient Greek riddle. It is no coincidence that people endowed with a long life by the Creator bother with their feet a lot, not because of any kind of disease, but simply because of the tectonic deficiencies of the skeleton. If someone is sick, we say (in Hungarian) that he "fell off his feet", if he dies in a battle, he has "fallen", if someone is spiritually failed, we 
are talking about a fallen man. Our standing position can be a symbol of human life, and our lying position is that of death.

Again, we can turn to Antique parables: the Greek warrior who stabbed his opponent: released the other's knees, the lying and sleeping man is similar to the coffined, stretched corpse, if the kinship between hypnos-thanatos (sleep-dream) and death is interpreted spatially.

It is interesting that this uncertain position and movement of man is only compensated by genetic development with a reduced - so to speak economical - sense of balance. The system built into a person's overly complex senses only provides a calm, "natural" feeling when standing and when changing one's horizontal position, and it is enough to create a certain feeling of excitement in other situations. The sense of balance is much more developed in many species of animals: it is enough to refer only to the cat: the falling kitten always comes to its feet, which the falling human body is unable to do. And the diver can perform complex and "artistically twisted" jumps only after a long practice, as his production is also controlled by brain activity. Just like juggling, which only humans are able to do, animals not. The toddler likes to swing - either on a common swing or on a carousel - because his sense of balance indicates an interesting "otherness" that is different from natural. This is why the tourist is dizzy when he is allowed to walk on the ramp of the Leaning Tower of Pisa or when he is ascending or descending in the inclining elevator of the Eiffel Tower. In addition, the human sense of balance needs to be complemented by the data transmitted by vision. (We are not talking about pilots of fighter jets, aerobatics, people screaming on roller coasters, because in these cases the natural blood distribution of the body changes suddenly, the effect of which is much stronger than the signal given by the sense of balance.)

Nevertheless, the vertical posture of man and the sense of balance that ensures this upright position play an important role in spatial perception and interpretation. This is because man carries within himself the 0 point of a coordinate system in which the vertical direction is dominant, thus, he considers all vertical lines and surfaces in his vicinity to be anthropomorphic and alive. In addition, the primary direction of movement of this unbalanced creature is "forward" - this is the second important axis in the system - and any rapid change of direction shifts him out of balance. Finally, man measures the distance and thus the space with his characteristic, step-by-step way of moving, similar to the way of determining the extent of objects with the dimensions of his body parts - elbows, palms, fingers, etc.

The second feature of the human body beyond the five senses is a group of phenomena that can be summarized as "muscle sensation". These phenomena can be triggered by data transmitted by almost all the senses, and natural acknowledgment is accompanied by a temporary physical change. Our body twitches at a loud growl, some awesome sight or sound makes our back stiffen and make our flesh crawl, our hair stands on end, and so on. It is a well-known simple experiment that the arm held vertically and strongly pressed against the wall, when released after a few minutes of pressure, begins to rise by itself. Ultimately, allergies, hypersensitivity, the body's 
unusual response to some external influence can also be classified here. From this group of phenomena that has not been precisely clarified to this day, this paper highlights one thing, the simplest and most important to say: the fatigue of the human body. Because our muscular system changes its natural state of rest after a certain time, either when standing, or when moving. We recall a well-known and often cited image: the athletic English guard in a bearskin cap, who, unable to bear the unnaturalness of being on long guard, falls out of line and lies there in front of his more "durable" companions. It is no coincidence that people are shifted quickly in the guard of honor, because not everyone tolerates standing still for a long time. And when marching (not just on an ascending terrain), after a certain distance, our muscles often indicate how far we have gotten, even if individual capabilities and practice modify the distances. Consequently, the sense of limit power soon develops in man's perception of space. Physically: the little child, happily toddling for a while by his walking parents, will start to whimper at one point to express his need "Dad/Mom come pick me up". Such exclamations, "oh this is just a hop away," or "it's certainly a one-day walk," are distance estimations translated into the language of our body. Muscle sensation thus nuances and motivates the perception of space individually, as any hike done with muscle cramps in my leg seems to be longer than the distance walked with rested feet.

When taking possession of the space, man gradually explores and reveals his surroundings. The sensory-transferred communications are summed up by the brain, which we have only recently known to act by cerebral hemispheres and transversely, and this internal symmetry of operation further strengthens the various symmetries of the human body. Rooted in this "mental duality" is the control of different human activities, the development of right- and left-handedness, and it even makes the functioning of the eye asymmetrical.

It seems necessary that the exploring person does not always start all over again. Almost from the very beginning, he uses the knowledge already learnt in gaining new experiences, simply because he can remember. And the "inputs" of the ever-enriching "database" are also measures of value, as they guide us in choosing between beneficial and harmful moments. Also, emotional threads are attached to the ability to think, which classify the pleasant and the unpleasant in a similar way - to simplify the complex process. The world of thoughts, the world of emotions and the world of imagination are thus determining forces in the interpretation of the outer spatial world. Because from all this, a specific conditioning develops, which uses a part of the space mechanically, differentiates it automatically, but also gives hints about the possibilities of undiscovered areas.

Attempts to determine the essence of the architectural space include this so-called location concept. By location we mean parts of space - natural or artificially created that stand out from their environment due to the intellectual and emotional content attached to them, and thus become more important to people than other places. Birthplaces of historical personalities, scenes of a famous historical event, a venue or lookout point offering a wonderful natural spectacle, a building considered mag- 
nificent and fascinating by everyone, etc. all have a distinct value. But there are also "anti-places" that provoke resentment, such as recent prefabricated LPS housing estates - to name just one example. But this is true for large scale just as much as for small scale, because not only the public opinion of a certain community, but also the individual prefers certain places to which fond memories are bound, which he often visits; while he cannott even look at the other location, where some kind of trouble, misfortune has happened and he gives it a wide berth.

These influences work very effectively in the judgement of space, even though they do not come from the location itself, but from man. The famous man's home may be a characterless, unstylish house, the historical monument is only a glory to its own nation and a shame to the enemy, the brilliant building was considered half a century ago to be ostentatious and parvenu, the interpretation of an admired natural beauty is just as changeable. It is enough to refer to the famous art historian, the father of art history writing, Winckelmann, who curtained the window of his carriage on his way through the Alps because he could not bear the sight of the senseless disorder of the mountains.

What has been said so far could be summarized as follows:

- the projection of physique to the environment determines the basic framework of human space, which is a constant factor,

- the generally interpreted sensitivity indicates the limits of the human body's load capacity and performance, which is also a constant factor,

- finally, man's world of thought, emotion and imagination spins a kind of network on the environment, the threads of which designate the ordinary, preferred, disliked, etc. fields, thus pre-forming a certain system of spatial values that varies according to the perspectives of time, even if there are "timeless" moments too.

\section{THE ROLE OF THE SENSES IN SPATIAL PERCEPTION}

The senses do not describe space with equal efficiency. However, one thing they have in common: that they capture not only the data provided by the environment, but also those coming from our bodies. Man is not only a "self-conscious" but also a "self-perceiving" being. I can taste the saltiness of the sweat dripping from my face into my mouth, my cracked lips, I can smell the evaporation of my body's youth/old state, its neatness or untidiness, the "smell" of my metabolic products. I can stroke my body, feel the shape and extent of my limbs. When I speak, cry, scream, or laugh I hear myself. And except for the top of my head, my nape, my back, and my buttocks, I see the humble vistas of the gestures done by my body and my limbs. Man can also perceive phenomena the source of which is himself.

Self-perception thus creates a narrow, yet multifacetedly nuanced spatial world. It is the origin of the wider environment from which our senses are able to obtain the necessary data. And organs, depending on how much they are bound to the body, to its corporeality (how "materialistic") or how independent of it (i.e., how "demateri- 
alized") they are, they have different "rank" in the perception and interpretation of space.

The most material sense is the ability to taste. It is no coincidence that the baby begins to explore the world through this sense as he takes everything into his mouth, "by analogy" to the mother's nipple. Because (if any other factor is involved in this process) taste is the primary information for him: if we dropped a lemon in his mouth instead of sweet breast milk, he would start grimacing and spitting. The means of taste are the lips, especially the oral cavity with the tongue, and the associated mucous membrane system. This sense requires direct contact between the organ and the "object", but it can also take place indirectly, e.g. when we "taste" a pollutant released into the air. In this case, although we get some information about the extent of the surrounding space in rest position, but in order to have a direct effect, we need to move. This can only be illustrated by an impossible analogy: if we get into a completely dark cavity, we will lick the wall for lack of a better idea and assume that we are in a salt mine. The sense of taste is alive during sleep, but no one can dream of flavors. However, man cannot lose his taste, no illness or pathological effect can destroy it, only in some very special cases.

Thus, the "tastability" of our environment provides only a few hints about its spatial properties. But since the discovery of space is a sensory process, the role of taste cannot be ignored.

The ability to smell is second in the supposed classification, and the information transmitted by smelling is often confused with that of taste. The means of this sensation is the nose, which protrudes slightly in the center line of our face, and (as an atavistic legacy) facilitates us in smelling. We have one nose, but with two openings. However, the number and symmetrical location of the nostrils are irrelevant as no one can smell differently with the two of them, but it is important that they are open to the outside and our smell is directed outwards. Our genetic development did not "consider it necessary" for olfactory to play some kind of leading role in the human body, unlike for many species in the animal kingdom, for which smelling is crucial to support life and even to survive. Hunters know very well from which direction to scout the game to prevent it from running away when sensing the human smell brought by the wind. For man, smelling plays a similar role only in exceptional cases - in an emergency (e.g. in the case of high gas concentration).

It may seem contradictory to classify smell as a group of "material" perceptions, because the smell, the odor is air-transmitted, and the data conveyor is an atmospheric medium. But the source of the scent and the smell is usually obvious - it is a flower, rotting body, fire, etc. - so, almost from the very beginning, man believed this source to be material - and he was right. However, its "ethereal" character is enhanced by the fact that a fragrance can evoke very old memories, and we know that in Eastern cultures, the cult of fragrance "swirls around" the image of a "pleasant environment". It can even control our dreams, even though we cannot dream of smell. Impairment or loss of sense of smell does not cause any significant shock to the human body. 
It is well known that women are more sensitive to odors and fragrances than men. Obviously, there is a cultural-biological reason for women paying more attention to the purity of their bodies than the average man and why they strive to disguise the perceived "negative" phenomena or artificially enhance the perceived "positive" qualities with perfumes. Workplace experiences show that female employees classify their male colleagues according to their smell, and the perception of slovenliness (an often barely unavoidable endowment) on the other can turn into resentment. Smell plays a significant role in keeping distance between people - called proxemics - because it designates a certain spatial range around the person.

On the whole, however, the sense of smell provides data for a rather narrow area, even if we are outdoors and a cloud of scent or the like is blown towards us by the wind from a distance. In enclosed spaces, the smell may indicate the usage of the room (so it may have a functional meaning), because we can decide whether we have entered a grocery, a hairdresser's shop or a latrine, even with our eyes closed. The stale odor of the unventilated room, the halls of the abandoned, uninhabited building gives us perspectives in time. So, it sheds light on the (mostly temporary) state of space rather than its extent.

Touch is a central sense and plays a significantly more important role in spatial perception than the two organs discussed above. Its tool is the skin, practically the whole "envelope" of the human body, so it is the only surface that can perceive a direct or indirect tactile effect on a person, coming from any direction in space, also knowing where the effect comes from. It is also important because skin is one of the keys to the survival of human life. Yet it is not a "circular" organ as the tactile sensitivity of the body surface is not the same everywhere. For example, it is quite different on a person's shoulder than on his fingertips, not to mention the erogenous zones. If someone pokes a person's back with two fingers and gradually narrows the distance between them, when reaching approx. an inch, the "victim" only senses one point instead of two. So here the incoming information is false, as opposed to those parts or surfaces of the body where the nerve endings are much denser than on the back.

Touch can be passive and active. We can feel the effects of airflow, heat and air pressure even in our resting position, or the wind can blow dust and rain in our face, something can fall on us, causing pain. However, the active touch (the "body contact" data collection I initiated) is also realized while standing, sitting, lying down, as we feel the ground with our feet or the presence, shape and extent of the couch with our body.

Movement helps the development of the tactile ability. The change of location makes each sensory function more efficient, making them more effective by the exploratory and data clarifying curiosity. But none of them is as important as touch.

The reason for this is man's earthiness. The force of gravity binds man to the ground, as a floor dweller; he is forced between the surfaces on the walkway and the objects placed on it just like another "object". Here is the (primary) life medium of man, in which he feels the strength or softness of the soil, the changes of its direction (e.g. the starter and landing steps of the stairs), the size, smoothness or roughness of 
the things at hand (their texture and fracture) up to the height of the extended arm. In contact with or colliding with the surroundings, with his body sides he can squeeze out the gaps or spaces that are left between solid objects. And man can do all this with his eyes closed, even blindly. For a visually impaired or blind person, touch is the best "aid" for spatial orientation and can also ensure their participation in intellectual life through Braille writing. It is worth to mention that touch can also be indirect, as we can feel the world through our shoes, overcoats, and jackets. We can even "extend" our tactile ability with additional devices, some kind of "prosthesis", which is not a substitute, but an extension. Such a device is the simple walking stick, and even more so the white stick of the blind and the visually impaired, as it is a tool of information and guidance beyond the dimensions of his body.

If someone strokes me when I am dreaming and I do not wake up, touching can cause some kind of change in my dream images, and generate new ones, but we have no experience of feeling something like that in the world of dreams. The sense of touch - along with taste and smell - is always "awake" even if the evaluation of its cues is different when being awake or asleep. Intense aging of the skin surface can be fatal for humans. Not because it loses this important informative role, but because it loses its ability to dissipate heat. This, together with many other phenomena, warns us that it is not enough to interpret the functioning of the senses separately. Their most characteristic manifestations are obvious (since without them we cannot speak of having five senses), but how one message affects, strengthens, weakens, distorts, etc. the other, so what kind of cooperation and relationship system can be found among them is difficult to trace.

Thus, touch is a great helper of man in the exploration and interpretation of his environment. Before the modern conception has developed, which interprets space as a process of all-sense perception, tactile sense was considered to be exclusively important besides vision. Because the role of touch in getting to know the world around us is almost as important as that of seeing in exploring distant perspectives.

After touching, the significance of hearing come in the order chosen. The ear is a rather complex organ. Located on both sides of the head, the ear has external collecting and deflecting shells to collect sounds that are "received" inside the organ where the balance sensing organ is also located. This duality and symmetry are important, as it allows a person to perceive the effects of the environment from the side, but also to recognize the direction and location of the sound source. The human ear is not so advanced as that of many animal species, yet it plays a multiple role in human life. For example, with the help of associations, the ear can also convey temporal perspectives: people remember the voice of their peers and are able to choose from many hundred sounds the already known accent, speech style, tone of voice. Which also means they can distinguish the nature of the sound sources.

Hearing is also an always-alert organ function, but its ability can be artificially reduced. For example, a person who is hypersensitive to noises can only sleep with earplugs. A sound effect can govern the images and actions of our dreams, and we can dream sounds: sometimes we wake up to a ring, even though no one has ringed. 
However, this is related to the fact that among the senses hearing is most exposed to hallucinations. There is no absolute silence (although such a room has been "produced" experimentally); a person in a completely silent and deaf space will start to hallucinate after a while, which may intensify to an unbearable level. Because man is surrounded by a circle of continuous and constant sound effects that anchor him in space. The end of noises creates a feeling of lack and attracts attention. It is a wellknown example that a sleeping miller wakes up immediately when his mill stops, and the "shocked" silence in the crowd indicates an extraordinary event.

Hearing sensitivity intensifies in the blind, or rather: his visual deficiency leads to consciously observing and evaluating other cues. A person born deaf can make himself understood with sign language only after a long practice, and since he has no voice memory, he can more or less learn to articulate words through imitation, with the help of sight. The sensitivity of the sensory organ is shown by the fact that hearing begins to deteriorate at a young age, presumably at the age of twenty, and keeps a sharpness varying individual by individual. Hearing can be impaired unilaterally, asymmetrically too, a person who is hard of hearing or deaf on one ear thus gets in an acoustically "tilted" position and tries to "restore" the balance by turning his head and changing the position. A person with a hard of hearing or deafness on both ears is forced to give up this type of orientation, which restricts and limits his movement, and deafness can even lead to dangerous situations. However, the public consciousness does not consider the limitation and inability of this sensory organ to be tragic.

One of the "magical" abilities of man is to be able to remember and recall musical melodies. A genius conductor can conduct the entire opera without blinking at the score, and Beethoven composed even after he was completely deaf. And to follow the influence of sounds all the way to some physiological depths, we cite the wellknown example: cows give more milk when they hear calm, soft harmonic melodies than when they hear annoying rhythms and cacophonies.

The inventive man then figured out how to alleviate hearing loss with a "prosthesis" of a hearing aid. Prior to that, he figured out that sounds could be diverted when he built an arched seating area to the theater, and that he could increase the volume by placing resonant buckets under the seats. With the development of technology, man could transfer sounds generated at astonishing distances right into the ear with complex inventions, and finally he was able to create some kind of audio-spaces with devices that created stereo effects.

Hearing, along with sight, is the "aristocracy" of perceptions because of the variety and richness of the communications it provides. It also plays a varied role in spatial perception, as we may be addicted to sounds, but can also be their master. The constant, almost unconsciously perceived "background noise" is inherent in space, so it helps us feel in space, even if we cannot rotate our auricula. Sounds can help our spatial orientation; sound reflections and echoes indicate the extent of space. The nature of the noises reveals whether we are indoors or outdoors, in urban or natural space. However, in a very simple way, e.g. by opening and closing the window, the 
two types of "sound worlds" can be connected and separated. With sound baffles, sound-absorbing curtains and covers, sounds can be controlled and eliminated.

Acoustics has matured into a prestigious science and now plays an important role in architecture. Especially in buildings designed for the "enjoyment" of sounds, like odeons, concert halls, operas, theaters. However, the recognition of hearing and sound playing an important role in the all-sense process of perceiving space is relatively new.

The organ of sight is the eye, the "king" of our senses. Its outstanding status is ensured by the fact that it has "detail-abilities" that could be evaluated on their own as individual perceptions: for example, in spatial perception color vision plays a more important role in itself than taste or smell. Because beyond color vision, we can determine the extent and shape of spatial objects and the space itself, and we can perceive the movements that take place in space, and even the "movement" of space in accordance with changes in perspectives. Perception of color-shape-movement is the most important of our eye's abilities.

The eye is our only sensory organ, which can be "curtained" both intentionally and reflexively. Sight can be paused with a staccato rhythm (blink) and permanently (sleep). On average, a person blinks 25 times per minute, 1500 times per hour, and sleeps 7 hours a day, so his eyes are closed for almost an hour from approximately 17 hours of waking time, if the blink of an eye is estimated at $1 / 3$ second. Consequently, the eyes are closed in 33\% of the 24 hours of a day and open in $66 \%$. The meaning of this automatism is that otherwise the flood of information and data conveyed by the eye could not be "tolerated and processed" by the brain, be any high-capacity, if the sense organ of vision, similarly to the others, was constantly "awake". Congestion is visible from the eyes: the architect, who was drawing all night long, looks with red and inflamed eyes into the shaving mirror in the morning.

With a "share" of about $80 \%$, the eye takes the lead in spatial perception. It is a mystery what Greek mythology wants to express with the one-eyed creatures of the Cyclops. However, what we know is that the position of two human eyes next to each other, even if the distance between them is relatively small, contributes to the spatial perception of objects. When we are alternately blinking our eyes, objects seem to move and jump. But only laterally, not vertically (unless we have astigmatism). Although the eyeballs are spherical, it is precisely due to their double horizontal axis that our vision "catches" more from the lateral perspectives than from the vertical ones. As a result, the visual field can be compared to a horizontal ellipse. The eye is a sensitive "instrument", it also senses movement in the "corner" of our two eyes, so the large horizontal axis of the ellipse can be $180^{\circ}$, but the vertical axis covers a much smaller field. There are several observations available to determine the difference, as well as studies on the fact that vertical vision is asymmetric, so the visual fields above and below the horizon are different. These nuanced differences are, in fact, irrelevant because the physiological endowments have resulted in an innervation that we see the world much more horizontal than vertical. And this is also reflected in the fine art reproductions of the architectural space: although no statistics were created on how 
many panel paintings are made in landscape or in portrait format, it can be stated that the former predominate. Imagine a stage arrangement or a cinema screen in a vertical format: it immediately turns out that nothing can be presented "above" and partly "below" the horizon because these fields are useless and meaningless. Not only does the force of gravity make man a floor dweller, but also his perspective sticks him to the surface of the earth. Thus, in the coordinate system in which the vertical direction is determined by the projection of human physique, the depth is determined by the primary direction of the man's forward movement, the horizontal axis is introduced and completed by the field of vision.

The ability of seeing is not lost during sleep, and it has been found that eye function physiologically follows what is seen in a dream. From the dream we remember colors, shapes, movements, and spaces in which many re-experienced or novel events took place. All this proves that even in dreams no one can get rid of their visual experiences gained awake. Thus, with some transcendence, vision is an always-alert sensory function.

The eye, like other senses, may be incomplete and have reduced performance with age. In case of other sensory organs, any deviations from the "normal" can be defined in a word or two, while for vision there is no limit of such "errors". Someone may be squinting, short-sighted, farsighted or - after a certain surgical procedure - can have tunnel vision, also color-blind, and even "space-blind" e.g. according to the laconic judgment of the tests used in the architectural entrance examinations. All of these are arguments to justify the complexity of this organ. Also, they prove the fact that no two people with "normal vision" see the world in exactly the same way. In connection with El Greco's paintings, several attempts were made to prove that the enervated elongation of his figures was not the result of the era or his particular artistic approach, but due to some kind of physiological extraordinaryness in the painter's vision, i.e. he "actually" saw people this way.

We may never reveal the blind born man's image of the world; we can only rely on assumptions. He can navigate in space only by relying on the information provided by other senses and on his movement experiences. It is more than likely that for him space is a complex emptiness consisting of almost independent directions, accompanied and bordered by continuous and gaping solid elements. Thus, for him, space is a set of lines and dots that "consists" of the localization of tactile objects, sound effects and sound sources. Even the blind can learn to read, so from the descriptions he can imagine something we call space. Thus, one can risk the assumption that the blind-born man builds up something what science calls the space of thought - in a way unknown in details but based on concrete experiences.

The spatial vision of a person blinded in his life is different. Just as the visual life of wakefulness continues in our dreams, the set of memorial images is not destroyed by the loss of vision. It is enough to cite the well-known example: Milton could not have written his Paradise Lost if he had been born blind.

The high rank of hearing and seeing in perception is also evidenced by the fact that although they are the most effective factors in spatial perception, most of the 
aids, supplements, and enhancers are invented for these two senses. Man has realized that he can use artificial procedures to increase the range of data acquisition by these two senses. To eliminate the visual impairment, man has long invented the glasses, the magnifying or demaginfying lenses. This compulsion-born invention became the starting point of the process that led to the observability of stars and cells. Thus, man acquired abilities that were only mentioned in fairy tales: he can see through the material or observe places where he himself is not present.

It is known that light is one of the basic conditions for spatial perception. It is well known how the fate of architectural development was influenced by the effort to let natural daylight into enclosed spaces. The introduction of artificial light (from the torch and the candle to Edison's invention) has not only extended man's lifespan, but also completed his inherent ability, that is, to create and perceive space.

Among the abilities of our eyes, sensing color-shape-movement is the most important in the perception of space. These factors act simultaneously and together, but since each has become the subject of separate disciplines, it is possible to approach the essence of these "sights" on their own.

a) Our environment is colorful. For the painter, almost only colors exist, but science also tends to see the most definite feature of our visual world in the diversity of colors. This may be because this quality gives the most concrete and "materialistic" statements about our environment, both literally and figuratively, and because we attach the richest associations to colors. The predominant colors in natural space: the blue of the sky, the gold of the sunshine, the white-gray of the clouds, the green of the trees, the brownness of the earth, the yellow of the sand and then the yellowing of the leaves, the whiteness of the snowy landscape, etc. or in close human relationships: the pink, yellow, and ebony of the skin, black and blonde hair, reddish of the living and the wax color of the dead, the red of the dripping blood, etc. are all important signs (spatial and temporal) in human relations with the environment and with each other, being known and understood since ancient times. Colors make space organic, because objects located in space can be distinguished by their different colors and thus, they become individual. At the same time reflexes and reflections from these surfaces fill the space itself with a lively, always changing "color atmosphere". It is no coincidence that man later invented the "artificial colors" with which he also revived his created environment. The "white revolution" of Modernist architecture, sprouting from abstract fine art, initially banished colors from its tool set, this way realizing the principle of less is more in this field too, also making the space itself abstract.

The colors transferred from nature to architecture gave rise to symbolism. In ancient Eastern architectural cultures, entire interiors were painted by imitating nature. From the line of later imitations, we cite only the best known: the spherical spatial effect of the domes was enhanced into a true "image" of the sky. Out of innervation and habit, certain colors then became popular: there was a period in our monument protection practice when most of our historic buildings were painted "K. u. K. yellow". 
At this point, we need to incorporate the observations of science into our train of thought. Successful attempts have been made to objectively define man's preference for color. It turned out that people of different genders, ages and education have different attitudes towards colors. The popularity of some colors and the rejection of others can be followed up from individual level to national self-awareness, as evidenced by heraldry. Apart from historical traditions (in other words: using white and red), most tricolors can be divided into three classes: blues, greens, and "mixed" groups, from which, with a good approach, the national character can be inferred.

Beyond this pleasing idea, the physiological role of color in spatial perception and spatial effect is more important. Within the framework of Americanism, i.e. performance-centricity, researchers sought out colors that stimulate workers and painted the workplaces accordingly (by analogy with the effects of dairy cows and music), as colors do not affect well-being equally.

However, from the point of view of spatial perception, the most important thing is the tone value of the colors (definiteness-darkness and softness-lightness). „It's so dark (so black around me) that I can almost bite it" - this saying can be used to express the "materiality" of a deep-toned environment. The darker colored object or space is full-bodied and we feel it close to us, while the brighter thing is more spatial and we feel it farther away, so the depth and lateral layers of space are arranged accordingly in our imaginations.

So, about the role of colors in spatial perception (which can be said about all our senses) it can be stated that the variants of the specific situation are intertwined in the properties of the a priori "attitude".

b) Our environment has a shape. Colors give the content of space, while shapes create the frame and skeleton of it. Our visual field is a shape itself, it has boundaries, which - even if we do not consciously perceive them - presumably draw a lying ellipse. The image field can also be compared to a stage opening or a TV screen, perhaps even more to the latter due to its blurred sides, illustrating the uncertainty of the shape of the frame. Within the image field, however, we see certain things: a set of surfaces.

Transferring a definition used for one sensory communication to the communication of another organ is accepted for the purposes of the visual arts. Common language is also full of such applications and solutions. However, science considers such a thing to be intellectually sloppy. The best known example, because it refers to the closest connection, is the musicality of poetic language. In the verses, "Ici bas touts les lilacs meurent. Touts les chants des oiseaux sont courts" Verlaine consciously arranged the vowels and thus composed a musical run. But we usually talk about the melodicity of Latin languages, or the noisiness and atony of Slavic languages, etc. Expanding the scope: in Hungarian hangszín (literally: color of the sound) is the term for "tone", which is actually transmitted in the brown tone of the famous singer Katalin Karády's chanson. Musicians, however, interpret this feature differently, in a more abstract way, but they can make it out. Taste and color effect are linked in such 
descriptions: "The color scheme of this picture is terribly mawkish; its coloring is too sweet" etc.

When we look for such an illustrative kinship for shape perception and sight, tactile sense can be mentioned: seeing forms is a visual touch. He strokes his loved one's face with his gaze, his eyes cling to the girl's blouse, "devours" her with his eyes: such sayings refer to scanning or "fingering" what is seen, when we run our eyes around our surroundings. The joking protest of the Hungarian saying, "everything to the eye, nothing to the hand" refers to some kind of interdependence of these two senses.

Touching with the eye means perceiving spots of color in different tones. There are surface tensions in our visual field that are resolved by experience. This teaches us to separate the set of surfaces and create images of objects and bodies from (part of) them. There is no spatial perception without a coherent background surface, and the (already interpreted) outline of the forms in front of it allows for orientation in space.

The view of nature is dominated by organic forms: tree foliage, shrubs, hills, mountain ranges and peaks, cloud clumps, shapes of different species of flora and fauna. But also "geometric" shapes can be found in nature: the disk and crescent of the sun and the moon, the arch of the rainbow, the "rosette" of the flower, the straightness of the sun's rays and the straight tree trunks. Just as the richness of colors in nature is the source of the formation of our color scheme, the proliferation of forms in nature is the source of human world of forms. The ability to recognize independent forms developed from the stereotypes of their relationships, the repetitions of changing and unchanging things, which later made it possible to create man-made "artificial forms".

The most important component of the diversity of shapes and relationships is the separation of the two main directions, namely horizontal and vertical. Related to this is the phenomenon that horizontal lines and shapes are considered shorter and smaller than vertical ones of the same size. An operated patient mentioned that when, after several weeks of lying down, his nurse helped him to learn to walk again, he exclaimed: "hey, I didn't even think you are so tall". Another well-known optical illusion that when a building demolished to its foundation is later rebuilt ("re-erected"), the 3D appearance of the house is perceived to be much larger than we would have inferred from its "floor plan", i.e. its ruined condition. This illusion also happens the other way around. So, it seems that the visual perception of forms is also affected by some kind of gravitational force, which makes the same object be seen differently due to its mere displacement.

Shape perception is the basis of space perception. In reality, all the surfaces-lines-geometric shapes - and their relations - that populate the world of forms are keys to concretizing space. These create spatial elements from which the structure of space is built.

c) Our environment is moving. Findings of zoological experiments suggest that the perception of movement is the most important environmental indicator for each species, despite their different "eye structures". This is also the case for humans, but it is probably not as important as for animal species. Movement can refer to the nature 
of objects and things (trees swaying in the wind, the surface of the water rippling and then plunging into the abyss, etc.) but what is more important the kinetics (Latin: motio) of creatures - or some phenomena that look like them - gliding back and forth, wandering, rising or falling in space, thus enlivening space. Kinetics marks off the direction and mode of movements possible to perform in space, but also shows the boundaries of the given environment. No coincidence, an environment without such movements is called a deserted space.

Initial art-theoretical speculations about space interpreted space as immobile. Soon, however, this "static" approach had to be supplemented with dynamics, as space shows a different image when viewed from different spots. A characteristic human way of moving in space is walking around, in Latin ambulatio, during which space can unfold as fully as possible.

What is interesting, however, that space moves even without the "alien" movements taking place in it or without its own displacement (that is, kinetics and ambulation). Namely, as evidenced by the sight of the images appearing in my eyes: it moves objectively, if not in reality. The secret of this paradox is the perception of perspectives, which can also be captured artificially by photography. To some extent, perspective view is a characteristic of space, which we perceive both when looking from a point of view and during movement - it is an almost "self-contained" phenomenon.

Representing three dimensions in two - in the plane - was "invented" and consciously applied by the ancient Greeks. Greek stage images were the first perspective images, these scenographies were the first perspective representations in the visual arts. Depicting spatial things on a plane is a matter of debate in Hellenic philosophy as a relationship between reality and illusion. Also, the same philosophy formulated the concept of space by separating the body (the soma) from the place (the topos), which the bodies "fit" in. The attempt to solve the issue of space intellectually has become the origin of the interpretation of many relevant phenomena, which led to the formation of a conscious vision of man.

Science claims that man sees the world upside down, which is reversed by experience gained very early in childhood. We should believe all this, but that is not how our vision works. We also had to "learn" the perception of perspectives, and the knowledge gained in this field has been kept, as everyone creates order in the various sights of his surroundings in this way. The professor of descriptive geometry has, of course, much more sensitive and subtle sense of perspective vision and view of space than the ordinary man. But the ability of the latter is also sufficient to take note of the basic perspective phenomena: that the object is larger when viewed from close than from a distance, the two lines of the pair of rails merge at infinity, the circular window is oval when viewed from the side, and so on - just to mention only the simplest optical theorems of Euclidean geometry. Architecture is called frozen music and the architect is a frozen musician. Well, modeled on this humorous analogy, let us test the claim that perspective is the totality of stiffened motional experiences. Between the close-up large and the distant small image of the object, there is the 


\begin{tabular}{|c|c|c|c|c|c|c|c|c|c|}
\hline 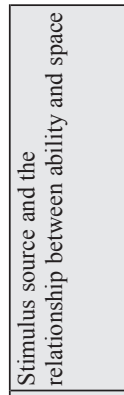 & 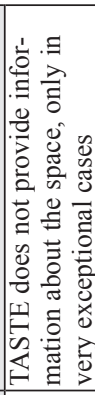 & 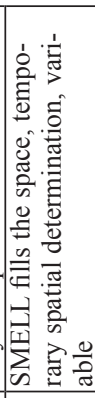 & 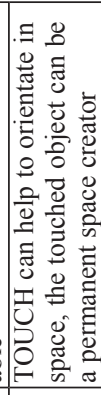 & 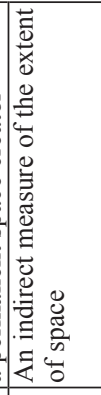 & 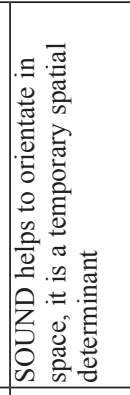 & 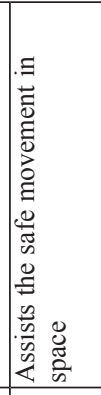 & 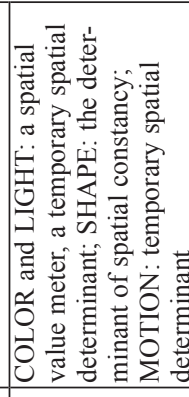 & 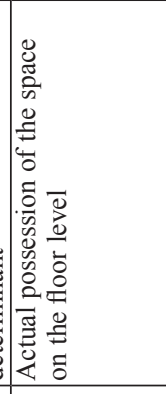 & 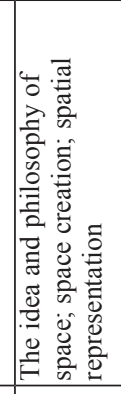 \\
\hline 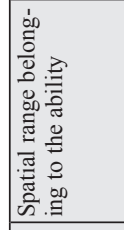 & 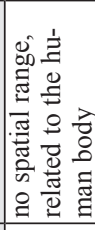 & . & 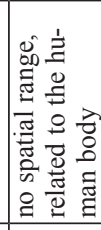 & 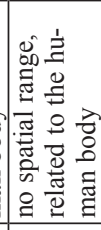 & : & 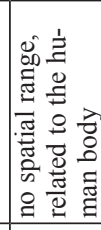 & : & 离 & 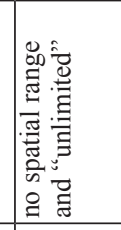 \\
\hline 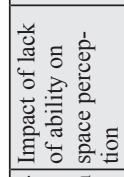 & 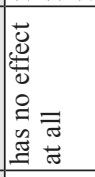 & 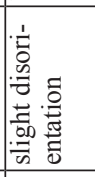 & 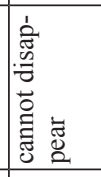 & 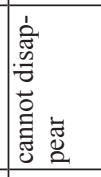 & 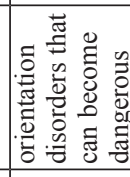 & 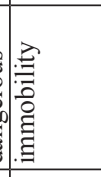 & 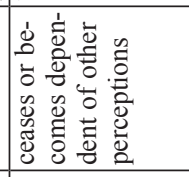 & 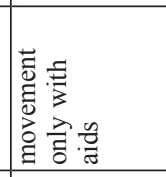 & 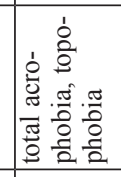 \\
\hline 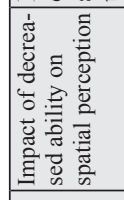 & 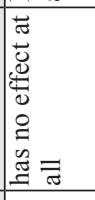 & 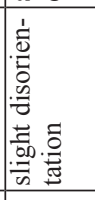 & 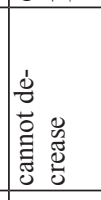 & 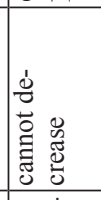 & 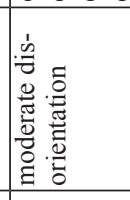 & 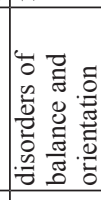 & 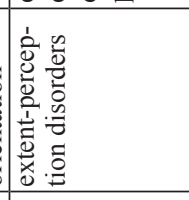 & 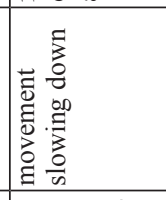 & 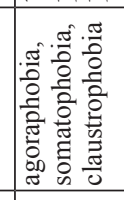 \\
\hline 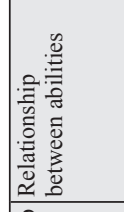 & 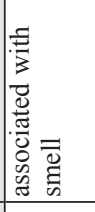 & 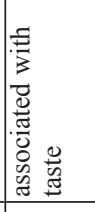 & 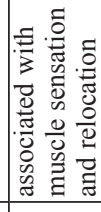 & 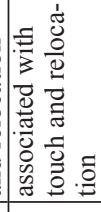 & 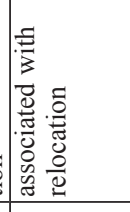 & 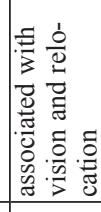 & 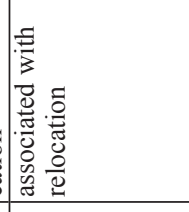 & 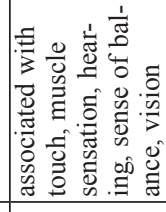 & 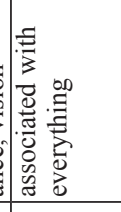 \\
\hline 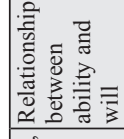 & 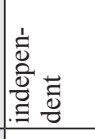 & 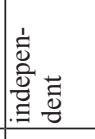 & 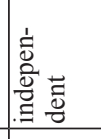 & 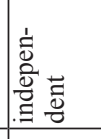 & 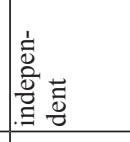 & 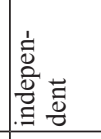 & 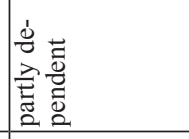 & 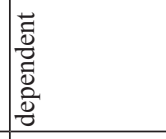 & 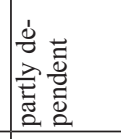 \\
\hline 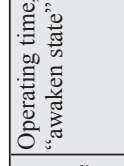 & 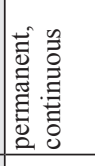 & 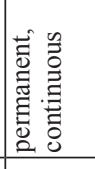 & 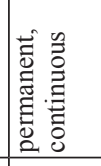 & 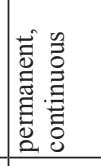 & 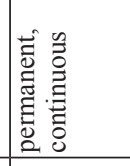 & 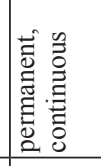 & 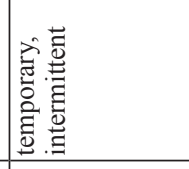 & 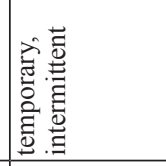 & 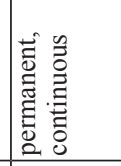 \\
\hline 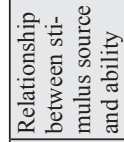 & 苞 & 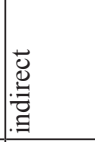 & 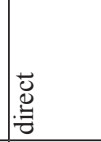 & 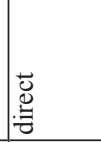 & 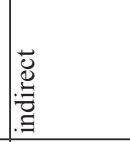 & 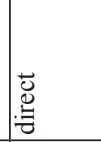 & 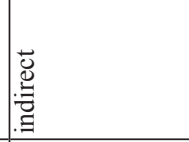 & $\begin{array}{l}\overrightarrow{\tilde{U}} \\
: \\
\ddot{\theta}\end{array}$ & 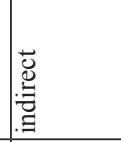 \\
\hline 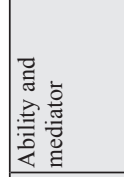 & 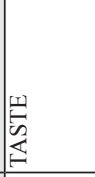 & $\sum_{\text {亗 }}$ & 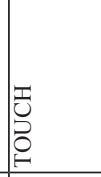 & 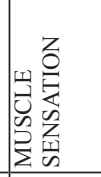 & 送 & 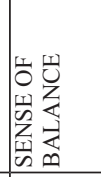 & 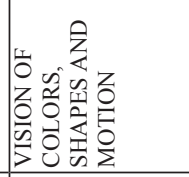 & 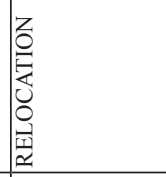 & 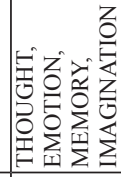 \\
\hline & - & $\omega$ & $m$ & A & $\ln$ & 6 & r & $\infty$ & a \\
\hline
\end{tabular}


experience of the journey to be taken in order to realize that the two objects are the same size.

When looking into a long corridor, the door that opens at the end suggests that we can get through it, no matter how small it looks. Because it is the same size as the door we entered. Between the two, there is our ambulatory memory, which makes this detail "move", together with the others, and shows the deep-running momentum of the corridor space. The sight of space is therefore not motionless, consequently "space is moving" because the "appearance" of its borders is in motion. Vision really plays a leading role in spatial perception, as we could break down motion perception into further partial phenomena. However, due to the position of the eye, visually we always just "look into" the space, the space is always "in front of us". After all, no one can see backwards at a resting position, even if we can observe a lobe-like area by turning our head. Even if we go back and forth "inside" the space, continuously looking here and there, we cannot comprehend the whole of space at once, because it consists of spectacles of space details. This is why other sensory communications are so important because they can complement this "one-sidedness" of vision.

The description of the function of the senses and their role in spatial perception is closed with a summary-like table, which also includes the characteristics of the other abilities (Table 1).

In the academic literature, different space types are usually denoted with independent names according to man's senses involved in spatial perception. Using the accepted names (by marking them) and supplementing them with new or lesser-known ones, we can refer to the different "images" of space with the following terms:

space of taste
olfactory space
space of touch
muscle sensing space
space of hearing
space of balance
space of vision
space of colors
space of shapes
space of movements
space of relocation
space of cognition or consciousness
space of recollection
space of emotions or mood
space of imagination
space of thought

\author{
saporal space \\ odoral space \\ tactile space \\ muscular space \\ auditive space \\ equilibrium space \\ visual space \\ coloral space \\ formal space \\ motional space (kinetic space) \\ ambulative space (kinetic space) \\ mental space \\ memorial or memory space \\ affectual space \\ fantasy space \\ cognitive space
}


The names are intended to simplify the references, but do not reveal the role of human capabilities in relation to space. Some suggest what can happen in space; others that space is variable due to the relativity of perceptions and movements, and there are terms that express what space means in terms of content and form. The modern conception, which sees the full understanding of space as the result of the total perception process, is obviously correct, because it has enriched the issue (which is not easy to interpret) with many new remarks. At the same time, it made the task more difficult as the nuance of the significance of the factors became more complicated.

Being "spoilt for choice" can only be resolved if fundamental truths can be found that serve as a basis for determining the role of other factors. One such axiom of getting to know the artificial, architectural space (which we are talking about now) is hidden in the so-called formal area of the visual space and revealing this can be our starting point. It is not known who gave the name of the Hungarian avant-garde magazine: Tér és Forma - Space and Form - (presumably Virgil Bierbauer-Borbíró), but he touched on the point, even though it is now untraceable, of how the association of the two concepts was interpreted at that time. Because our first axiom to be defined can be deduced from this, without "and": architectural space = form.

The comparison of human senses reveals not only what has been known so far, i.e. the fact that visuality is the most important thing in space perception, but also that the eye perceives the constant space-creating factors, serving as a framework and opportunity for everything that can happen with and inside the space. Thus, the threshold of understanding must be crossed by examining what we have gotten into, instead of immediately analyzing the impressions like something is emitting an unpleasant odor, the ground is gnarled, the side borders of space are rough, its acoustics is pleasant, it is painted distastefully, or how long it takes to get to the end with my freshly casted, broken ankle and that it reminds me of something I do not like or bear.

It is hard to separate the factors involved in the total perception process because man is immersed in this whole at once. Yet, in addition to acknowledging the existence of spatial boundaries that create space, an attempt should be made to discover whether these existing features are capable of exerting effects that are more objective than other factors.

And this is only possible by analyzing form itself.

\section{CREATING THE ARCHITECTURAL SPACE}

In the course of learning about space, it has presumably been clarified how much richness and diversity this "intangible" medium provides while becoming the scene of human life. The abundance of perceptions, impressions, and image associations rightly raises the assumption that if something seems so complex, it cannot be homogeneous. However, in our hasty judgments, space seems like a uniform emptiness. We think it only serves as an opportunity for things or objects to be placed some- 
where and to get somewhere. Well, space - more precisely the human space - consists of different parts. Therefore, it means that the factors, necessarily, relate to each other. Consequently, human space has an order, if you like, human space is structured.

\section{LAYERING OF SPACE}

The basis of our assumption is rooted in the ability of seeing forms. This time, we need to talk not only about what space is like as a sight, but what it really is. This fact-finding investigation will inevitably lead to our world falling apart to pieces.

It has been said that the force of gravity "glues" man to the ground. Therefore, the primary habitat is that layer of space the bottom of which is the ground level and the top of which is where the average person can reach with his extended arm. This is the zone of the tactile space, at the same time, that of the ordinary, standard relocation, i.e. ambulation. The analysis of looking/seeing revealed that the horizontal extent of the world we experience every day is greater than the vertical extent, which enhances the feeling of attachment to the ground level. The walking surface of the environment is a natural characteristic, which, if there is no special reason for it, we do not even pay attention to but accept automatically, so it almost latently creates the "bottom" of the human space in which we live. It can be stated that man is not a space dweller, but specifically a floor dweller. And where he actually exists is the bottom of space, the fundamental space.

The point of all this is that human space is bound to the material, which "takes shape" as a surface. The walking level is the first such surface, as it is the primary condition and root of life. It is also an important phenomenon that all shapes and forming factors (lines and surfaces), the direction of which is the same as the walking level, so they are parallel to it (i.e. horizontal), are perceived to be more constant and almost neutral than other directions.

It is likely that vertical forms bring vitality and life to human space. What stands is alive and getting upright is ultimately a human-like momentum. Man must attach ascending elements to the horizontality of the walking surface in order to separate one's chosen area from the infinity of space and bring it to life. Creating a man-made space requires side boundaries.

Numerous witty studies have shown that the experience of the first man who discovered the benefits of a cave was the starting point when a creature so vulnerable to nature became independent of it and changed his whole way of life and attitude. The assumption of the defining power of the "cave experience" and its survival as an atavistic heritage can answer many questions and is thus acceptable. However, the prehistoric man did not immediately make an "artificial cave" for himself. The history of the development of architecture shows that the transition did not take place so directly. The conquest of the outer space began with the establishment of simple fences and enclosed spaces. 
The idea arose in the workshop of philosophy: the fate of architecture is determined by the development and advancement of covering space from above. The magnificent barrel vaults, cloister vaults, domes, the brilliant coffered ceilings as well as complex supports and roof structures designed and timbered with a lot of "headaches" are - so to speak - the parts of a building in the creation of which the technical-artistic sense, ingenuity and engineering skills of the constructing man are most spectacularly manifested. Vaults, domes, flat ceilings, open roof structures are the "crowns" of space (both literally and figuratively) for these make the space complete and covered. The literature of art history adapted this idea, and even those who defined architecture as a spatial art believed that the greatness of ancient Roman architecture, for example, was created by the Romans' high level of knowledge in vault construction. They were convinced that only a covered space could be called architectural space. Also, today's prominent theoretical experts consider only the inner rooms, the interior, to be space.

However, this perception, widespread in both scientific and everyday thinking, takes into account only one possible (final) state of space, but it skips how space is created, how man creates his own spatial world. It is hardly debatable that neither the streets and squares of settlements, villages, and towns, nor the inner courtyards of the houses themselves - that is, the outdoor spaces - can be considered inferior architectural space. The boulevards of Paris (e.g. the Champs Elysée) or the piazzas of Rome (e.g. Campidoglio) cannot be excluded from space-aesthetic studies. The architectural space is Janus-faced, because its structure and the degree of its articulation are formed according to the same laws inside and outside.

We can create the illusion of a floating roof, but we have to support the ceiling with walls or columns/pillars. In the creation of space, the establishment of side boundaries is of primary, and its coverage is of secondary importance. And not only in time, but also in significance. As man meets rising surfaces everywhere in the artificial space, we can say that man lives more within walls than under ceilings. That is enough to delimit the primary living space layer, the fundamental space. Obviously, different forms of coverage have influence on the spatial effect, but, to put it absurdly, if there was no rain and snow, if the wind did not carry sand and dust, if sunlight were not unbearable sometimes, etc., there would be no need to cover the space. So, we tend to attribute glory not to the ceiling but to the walls, as opposed to the philozophizing mentioned earlier. It is even more so because this way the frameworks of human life outside the house walls do not have to be excluded from the group of architectural spaces.

The supposed "secondary" role of spatial coverage in spatial perception is also confirmed by our behavior. This is because the ceilings rise and expand above the fundamental layer of space at a height that we cannot reach with our hands, only with our eyes. Above the fundamental layer - without any visible separation - another layer begins, which, supplemented and integrated up to the ceiling, gives out the full "thickness" of the space. And the overlays are located in this integral zone of space (the secondary living space of man) a little far from me and out of my direct field of 
view, as I rarely turn my head up and raise my eyes to the ceiling. Since the ceiling is not constantly in front of my eyes, I "tacitly" acknowledge the field that is above me, but I do not constantly perceive it, so it will be a visually round experience only in the perspective of the space, together with the floor and the side borders.

We can therefore boldly state that the lateral boundaries of space are the highly emphasized elements of the creation of space both in the actual creation of space, that is, tectonically, and in the light of our behavior, that is, according to the indications of our abilities. And they are most pronounced where they "grow out of the ground" - that is, in our primary living space, in the fundamental layer - and right near the space delimiting surfaces. This can be proved by an urban design example, taken from outdoor spaces. On one side of the street, bordered by multi-story houses, stands a ground floor building. A man who walked along this side every day was asked if there was a ground floor house in the street. He was embarrassed, he had to thoroughly think about the answer because the façade of the ground floor house, being as high as the commercial portals of the multi-story buildings, melted into a uniform and "monopolistic" lane. The bottom line of sight was fixed in the interviewed person, although he knew that there was a ground floor house here, as he had seen it many times from the other side.

The nature of the upper spatial zones being latent in our consciousness has also been experimentally confirmed. In the aula of the Technical University, we created different perimeter shapes: square, rectangle and circle from the $2 \mathrm{~m}$ high and $1 \mathrm{~m}$ wide screen wall elements used for exhibition purposes. The problem was whether these boundary elements, or the "walls" made up of them, were not too low. Has the examination of the specific features of the delimited space unit no influence on the view revealing over the temporary space walls: e.g. the columns of the upper floor of the hall, the glazed transparent ceiling, etc.? It turned out that this lateral boundary height, which roughly corresponds to the thickness of the fundamental space layer, was exactly enough to allow the experimental program (the impact assessment of the changes in the direction of the lateral boundaries and that of the spatial forms) to be carried out smoothly.

The vertical layering of space is a given structuring of space. After all, when walking anywhere in nature - on a plain, on a hillside, on a mountain ridge - we stay or move in a spatial "carpet" adhered to the surface. Above it unfolds the infinity of space, which is lost in the spherical horizons.

However, natural spatial layering will become artificial if we "captivate" it within the walls of the house. The difference on the ground floor of the house compared to the outside world is that the zone above the fundamental layer - which is the spherical space outside - is shortened and molded into a form and transformed into an integral spatial field under the ceiling. On the upper floors, then, the artificial intervention is even more obvious, as the slabs separating the levels "recreate" and repeat the primary living space. As a result, the fundamental layer can be ranked one above the other by separating the integrants. In the case of skyscrapers, this layering can be repeated as high as technical conditions allow. Thus, the rooms on the thirtieth 
or fortieth, etc. floor and on the ground floor have the same spatial layering state. And if the rooms have the same shape, then the whole structure of their space is the same. Although not completely, as the approach of the rooms upstairs or on the ground floor is different.

\section{ELEMENTS AND RELATIONS OF SPACE}

The role of the lateral boundaries of space can be interpreted in a similar way as that of its walking level. The walls of space are delimited here and there by surfaces, and these surfaces - quite generally - serve the safety of our life. We are actually forced to cling to the floor (by gravity), but walls only attract us because we feel them similar to us and see them as our helping companions.

There is a French proverb but instead of quoting it literally we refer only to its essence. The essence of things or phenomena is mostly characterized by their anomalies, kind of "failures" - this is how the dialectic to be accepted sounds. A person with an agoraphobia almost panics if he must go through a spacious area. He can only walk safely next to the wall. Such a "man by the wall" is the citizen who has a healthy, normal sense of space, but also a humble and shy attitude, who never marches in the middle of the corridor proudly, but sneaks by the wall, and who never sits down in the restaurant at one of the middle tables, but gladly settles in one of the side boxes. The elderly is looking for the handrail since they can only go up and down the stairs when grabbing it, and not just the actual holding gesture plays a role in this. When guiding a visiting professor during a sightseeing tour, I noticed that he was carrying two small, heavy-looking suitcases with him in both hands all the time. In the end, it turned out that he was suffering from an imbalance, and the suitcases served as supports for him, because he loaded them with bricks. So, he could always feel the "fictive wall" that provided security when walking. The example, the analogy is a bit awkward, but "there's something in it" that could be useful for conveying our message. Claustrophobia - the sickly distressing feeling of being surrounded justifies the effect of spatial boundaries on a person the other way round: the sufferer wants to break out of even such a space in which many others feel normal.

It would be a bold assumption to say that there was some magical force flowing from the side boundary, and that something like "surface attraction" works. What is certain, however, that there is one kind of space near the wall, another one, when moving away from it, and a third one, if someone is standing or moving in the middle of the space. It is not about simply being at a different distance from the wall, but about entering a zone with a different quality of space. This is because there is a so-called peripheral spatial belt along the walls, which feels more tangible and thus denser (as considered to be at a "palpable" distance from the surface). Where the row of peripheral spatial elements loses its strength and dies there is the zone where the spatial field begins to extend and spread, which is more airy and rarer than the one by the wall. Thus, in the structure of the enclosed space, the form-induced peripher- 
al row of elements embraces the spatial field created by the spatial elements. Similarly to the invisible boundary between the fundamental and integrative spatial layers, there is a line between the peripheral and spatial zones. And most importantly, these boundaries are not only created in the human imagination, because when man pulled up the walls, he created the spatial structure objectively, and the structure of space was created spontaneously.

By building the wall, man creates form, more precisely, the elements of form. We are not talking about the shape, articulation, decoration, or desolation of the wall, but simply about the fact that man compared two surfaces to each other: he likened the horizontal plane, the walking level to the vertical one - just to take the simplest and most common case as a basis. From this comparison of the surfaces (forming a flaring and therefore concave shape), a spatial relationship develops, i.e. the spatial zone enclosed by the two surfaces, which was called the peripheral row of elements above. When moving on, we find that the wall turns, forming a corner. Again, a flaring, concave form element, although not in a horizontal direction, but in an upright, vertical position. This deviation of the surface relationship from the previous one makes it easy to see that a new and different spatial relationship is created here. Looking up indoors, we discover the surface connection between the rising wall and the ceiling. Again, a concave element of form, which we rightly assume - because it is far from us in the integral spatial layer - that it "generates" a third kind of spatial relationship.

And if the experimental room is a corner room, then when looking at the house from the outside, we find that the walls turn at the end of the house, but in the opposite way, as inside: they are not concave but convex, i.e. turn in a full-bodied, "articulated" way. From such a "peaky" connection of the surfaces, we can hardly imagine that it could initiate the same spatial element as the flaring situation. Finally, getting out to the flat top of the house and approaching the edge of the roof, we find that the horizontal surface disappears because it "turns down" into the vertical plane. Due to the convex surface connection in a horizontal edge, the development of the accompanying elementary spatial relationship is a consequence of the mass-like nature and spatiality of the house.

In summary, we can state that there are only three kinds of flaring (concave) and two bodily (convex) spatial elements or elementary spatial relations, which, intertwined with the properties of vertical and horizontal spatial layering, create the structure of the space.

\section{FIVE TOOLS FOR CREATING SPACE}

There is no spatial perception without a continuous background surface - this is the basic premise of the scientific definition of vision. In spatial vision, therefore, the surface dominates, it is the orienting and directing factor. The analytical experiment 
of space assumes essentially the same thing, or something similar: real space is created through surfaces and surface relations.

The reality-value of this conclusion and statement that can be judged to be quite theoretical (in big words: logical), requires empirical confirmation and experimental results. In order to clarify substantive issues, we managed to conduct case studies, the aim of which was to follow the genesis of the artificial, man-made and architectural space.

The series of experiments was led by a small group of professors at the Budapest University of Technology, and the executors were second-year students of architecture. The experimental group therefore consisted of graduated architects, who set the tasks based on a certain theoretical concept and to-be architects who did not know the theories of architecture in detail and in depth at the beginning of their studies. The goal of the experiments was to actually confirm and justify the assumptions, but with actors who are ultimately impartial. This circumstance ensured the credibility of the results, of course, with the reservations that always come with the experiments (Fig. 1).

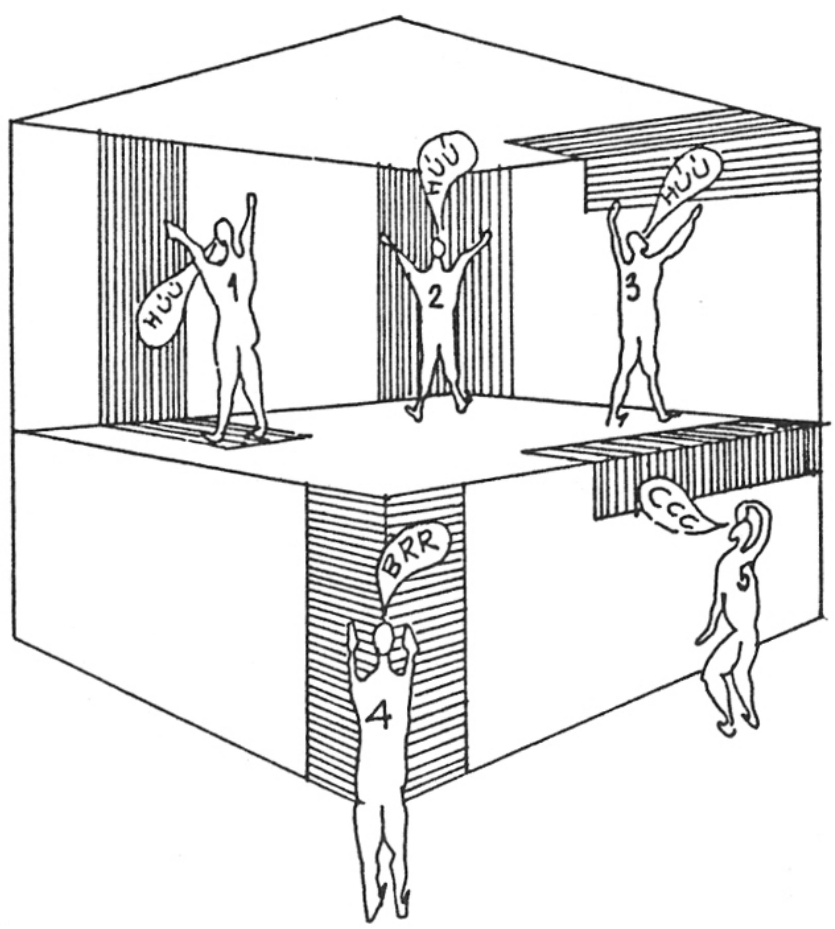

Figure 1. Five tools for creating space

1. Base-line, heterogeneous irradiation; 2. Base-line, homogeneous irradiation; 3. Additional heterogeneous irradiation; 4. Base-line, homogeneous dispersion; 5. Additional heterogeneous dispersion 
Base-line, heterogeneous irradiation. The first task of the series of experiments was to observe human behavior near the rising spatial boundary. As this environmental situation provides the basis for all other tasks, the experiment was repeated and performed by several groups.

Several issues were awaiting clarification: the examination of the extent of the vision field and the comparison of the empirical results with the values given in the academic literature; whether the visual assessment supports the assumption that the peripheral spatial belt along the spatial boundary exists at all, and if so, where is the boundary that separates it from the spatial field. Finally, are there any other forces beyond the sight itself that influence the "by-the-wall" behavior? Performing the following movements has promised to provide satisfying answers to the questions raised:

- perpendicular approach to the surface,

- moving away from the surface,

- walking along the surface, parallel to it at approx. two arm's length, up and down, completed with an ambulation with eyes closed.

Of the several sites proposed, the northern side of the Buda Castle seemed to be the most suitable for conducting the experiments. More precisely, the section of the castle wall behind the Museum of Military History, together with the pedestrian and playground area beneath. The selected environment was not "perfect" either, as up to the bottom of the $1.2 \mathrm{~m}$ high parapet wall (which forms the crown of the $10.78 \mathrm{~m}$ high castle wall), the wall plane is inclined inwards by $1.3 \mathrm{~m}$, so it deviates slightly from the perpendicular line. Although the grassy ground of the park is generally horizontal at the foot of the wall, its surface is broken by some minor unevenness. However, these conditions did not have a distorting effect on the results of the experiments.

The visual proof of the existence of the peripheral spatial belt depends on whether we can determine the distance from where the upper end of the vertical surface is still visible, and starts to disappear when moving from that spot inwards, toward the wall. Translated into optical language, this means the degree of the vertical angle of view above the horizon with a still, straight head posture. According to the data in the academic literature, this value is $40-45^{\circ}$. Based on the experiment, which took into account the participants' individual eye heights from the ground (setting the values between 1.5 and $1.75 \mathrm{~m}$ ), the angles of view above the horizon varied between $36-50^{\circ}$, but values between $36-41^{\circ}$ predominated. Thus, there is no sharp line between the peripheral spatial belt and the spatial field applying with the same distance to everyone, but it is a transition zone, which in the case under study was about 5.0 m wide (Fig. 2).

Participants in the experiment were asked to describe what impressions, feelings, associations of images and thoughts, etc. were triggered by the environmental situation. The following responses were given, which we cite in their spontaneity:

- The castle wall is reminiscent of a natural shape, the bank of the river or a riverbed. The wall is a "challenge", encourages me to climb on it. It feels good to feel small at the foot of the wall; 


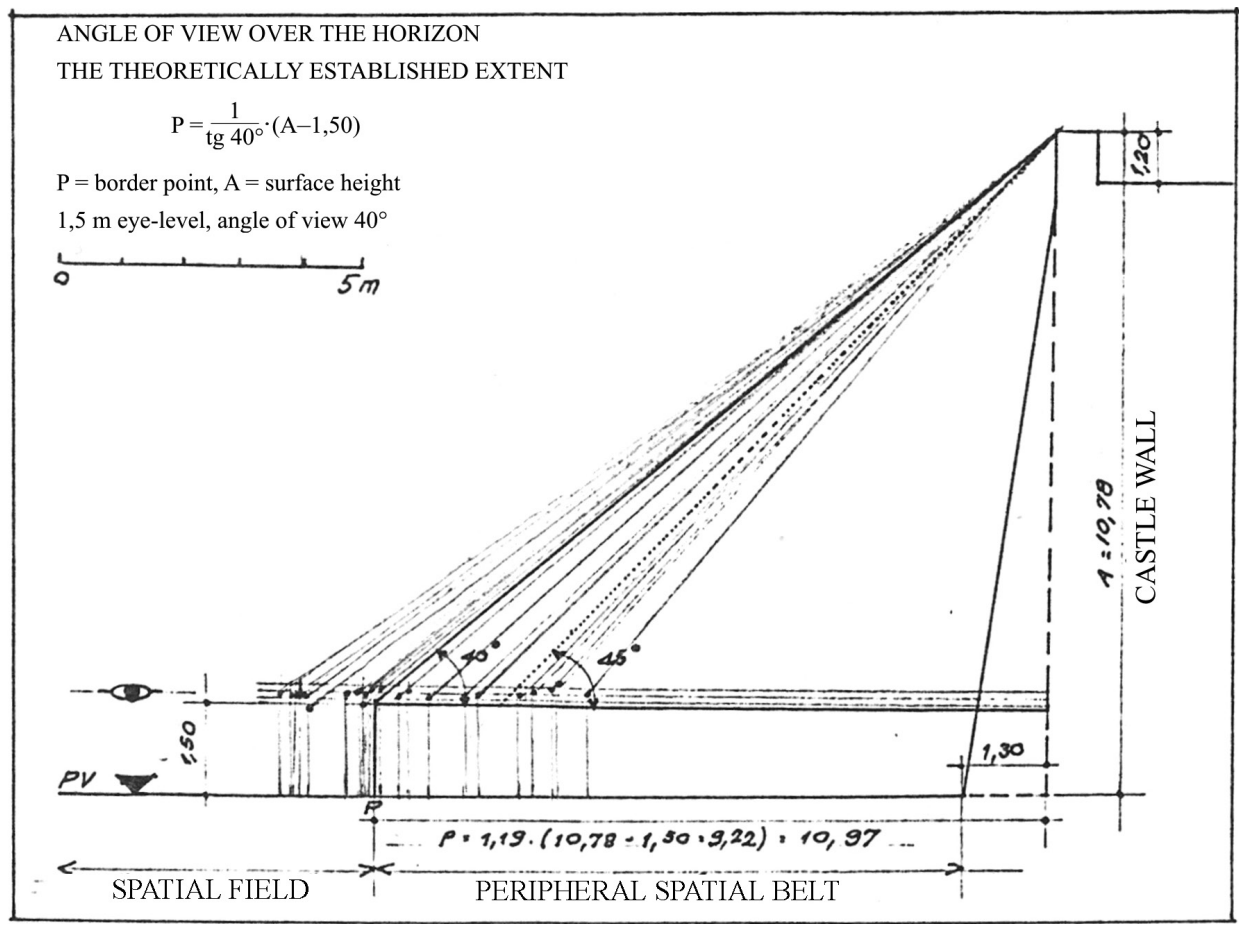

Figure 2. Angle of view over the horizon

- I feel small under the wall, the smaller the closer I get to it. It gives me a sense of stability;

- I want to get as close to it as possible, it attracts me;

- I wonder what is in front of the wall. I felt being "inside" something when I felt the delimiting nature of the surface disappearing;

- It is better to go by the wall than to move away from it. When approaching the wall, I know where I will get exactly, if I turn my back and leave: I feel insecure;

- The wall is the boundary line until my world reaches. I don't know what's behind it. Looking at it from a distance, I have the feeling that it is not mine;

- The overall view of the wall is uncharacteristic and diffluent from a distance, but attractive when approached to a certain distance;

- When approaching the wall, it "covers me", it gives a sense of security. Moving away from the wall, it still follows me, but soon becomes neutral;

- Approaching to 5-6 m, the wall still repels me, but then it attracts me and generates a pleasant feeling;

- The wall attracts, repels and even oppresses. If I move away from it, I feel better; 
- Approaching the wall, when I can no longer see the top edge, I feel insecure. It's even uncomfortable until I get to the foot of the wall because it's already good there;

- From a distance, the wall is "acceptable", approaching it becomes scary at one point, but when getting closer it becomes "acceptable" again;

- Approaching the wall, there was a point where I felt uncomfortable, but that feeling disappeared at the foot of the wall;

- When I look at it from a distance, I have two basic feelings: the wall is an obstacle, but it creates sense of space. As I approach the wall, the space is lost, and the obstacle remains. Turning my back on the wall, I feel secure, but also insecure because the space is open at the top;

- The wall forces me to look up, looking for where the top is. I have a depressing feeling at the foot of the wall, which I don't feel from afar;

- Approaching the wall to a distance of $1 \mathrm{~m}$, it was a pleasant feeling and I didn't feel the area at the foot of the wall depressing;

- I see a large mass, I am curious about its extent and what it hides: I want to go around it;

- I didn't want to approach it, but when I got close to the wall, I wanted to get in physical contact with it, I started scratching the surface and I wanted to climb on it. Also, I felt it provided protection.

The separability of the spatial zone in front of the wall in a concrete visual way, together with the experiential responses consisting of ambulative, tactile, balance perceptional, memory, imaginary, emotional and thought elements, clearly justify that the structuring of space is started. Because it is true that some professional, architectural "infection" can already be traced in the answers of the participants, and that the interpretation of their attitudes often contradicts each other, nevertheless it is hardly debatable that under the influence of the wall, in its vicinity some kind of "fermentation" starts. Thus, already in this phase of the experiment, the elementary spatial relationship, which can be called base-line heterogeneous irradiation (scientifically: fundamental heterogeneous conspersivity), is outlined, where "heterogeneous" means that the connection of two different surfaces (the horizontal walking level and the vertical space boundary) generates or initiates the formation of the space element.

Examination of the peripheral spatial belt also provided an opportunity to determine the perceptible range of vision below the horizon. In this regard, there are very extreme values in the literature.

According to one presumption, the vertical vision is asymmetrical, the angle of view is $40^{\circ}$ above the horizontal viewing radius and $20^{\circ}$ below it. According to the other opinion, the value below the horizon is $65^{\circ}$. The experiments confirmed the correctness of the latter data because the limits of the measured angles were $54-70^{\circ}$. This means that when approaching the wall, the crown part of the wall disappears from the field of vision earlier than the hinge point of the ground level and the rising spatial boundary, i.e. the foot of the wall. Thus, in the spatial element of the base-line 
heterogeneous irradiation, among the two initiating surfaces the perception of the walking level is "quantitatively" dominant, although it is a latent surface on the level of consciousness (Fig. 3).

Just as determining the value of vertical viewing angles is important for sensing changes in the direction of spatial boundary surfaces (at the top: for a free-standing wall, the termination of the surface, and for a covered wall, the connection of the wall and the ceiling, at the bottom: the breaking point of the walking level and the rising spatial boundary), it is equally important to know the horizontal sensing ability of the eye. In other words, the distance within which the change of surface direction can be detected laterally. The literature determines this value between $35-45^{\circ}$, adding that the movement is still perceived at $90^{\circ}$.

The experiments resulted in very diversified data. The experimental situation was designed in such a way that two rods were placed at the base of the wall at equal distances $(4.5 \mathrm{~m}$ each) from the set axis to indicate the boundaries of the field of view to be examined, i.e., the assumed change of surface direction. It turned out that half of the experimental participants saw laterally symmetrically, the other half asymmetrically; and half of the latter group did not perceive the left landmark, the other half

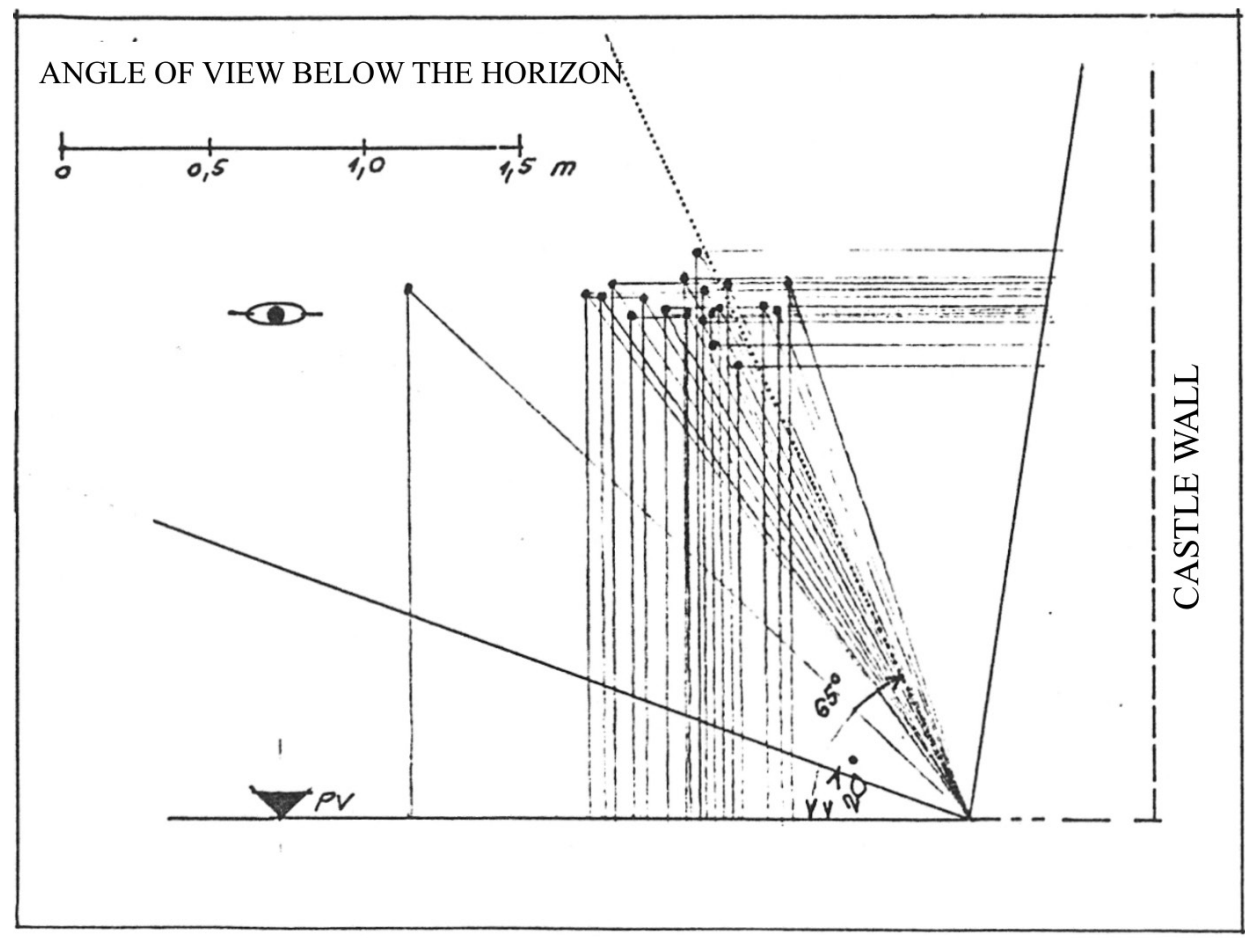

Figure 3. Angle of view below the horizon 


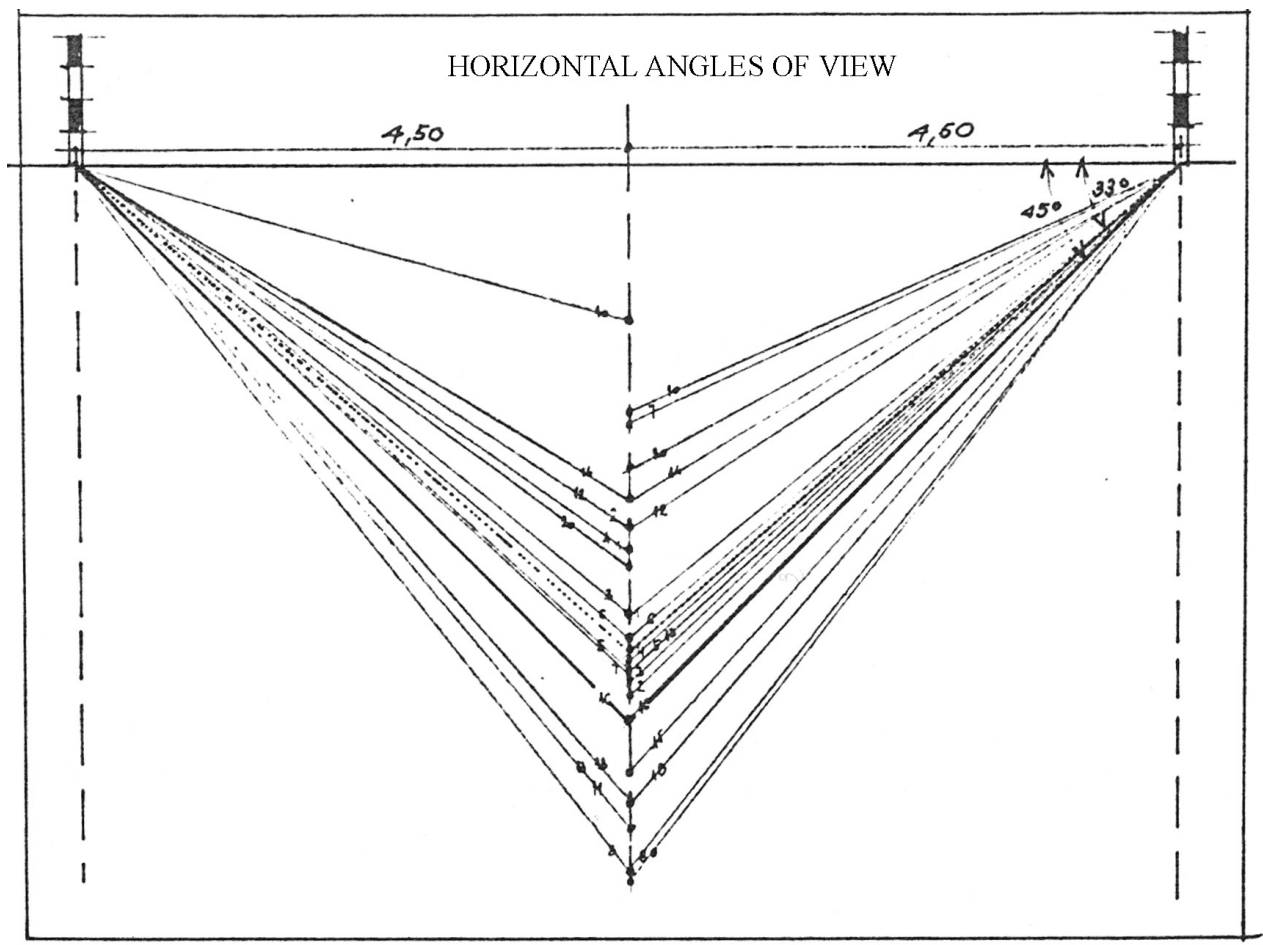

Figure 4. Horizontal angles of view

the right landmark in the same way from the same place. Symmetrically sighted people usually reported the disappearance of the surface turning points from a larger distance.

From all this, it is concluded that the vertical vision of the eye is more limited. Data measured by "experiential optics" get denser in this direction than in horizontal vision, where the limit values are very variable laterally. Perhaps it is not bold to assume that the reason for this is that the vertical extent of the field of vision is smaller than that of the horizontal one (Fig. 4).

The analysis of the elementary spatial relationship of the base-line heterogeneous irradiation was completed by observing the movement parallel to the wall. First, the participants reported their experiences of walking along the uninterrupted wall and then along a wall section interrupted at the beginning and end. The experimental site was the same as before: the bottom of the castle wall.

Walking at the foot of the continuous wall encouraged some participants to do some mimesis. Some claimed that they wanted to walk by the castle wall with sloped, dropped shoulders imitating its tilt, but there were also those who leaned away from 
the wall. It would require a deeper analysis to interpret the behavior that the proximity to the wall on the way back and forth did not evoke the same feeling. The right-handed experimenters, when the wall fell to their right on the way, felt anxiety; while backwards they were relieved, saying it was good not to feel any barrier by their right side. And left-handed people claimed the same thing the other way round. So, their tactilely more active and sensitive side required looseness.

Walking from one corner to the other along the demarcated wall section (about a $15 \mathrm{~m}$ long bastion wall) has answered the question whether the quality of the space changes at the corners or in front of the center of the wall. This is how the experimenters formulated their impressions:

- I felt myself in a large hall as I passed around the middle of the wall,

- At the beginning I felt tension, in the middle this feeling was dissolved, and at the end it decreased,

- I could see the start and the end of the wall from the beginning, so my overview was definite, but in the middle, it became uncertain,

- When I "entered" at the corner, the space narrowed, it was calm and safe in the middle, at the end the whole thing expanded,

- It is marked at the beginning, the space is lost in the middle, and it opens at the end,

- The start sets the direction, it is a safe feeling in the middle, and something is lost at the end: freedom.

The spatial area in front of the center of the wall is therefore qualitatively different from that at the corners, so the base-line heterogeneous irradiation can be assumed to exist in perception also in the horizontal relations.

The summary interpretation of the first - and basic - spatial element must be supplemented with an important thing. Archaeologists have proven that prehistoric man often settled at the foot of shore walls and rock sides, in the so-called abri $=$ rock shelter. Simply because this vertical spatial "bay" actually (so physically) provided them with protection. Since the shore side provided shade, protected the prehistoric man from the wind and rain, but most importantly: it secured his back against all kinds of attacks, so he only had to watch ahead and look around sideways to notice the dangers. So, this part of space meant security for him, an attractive place that was suitable for staying and settling down. The notion of "place" used for the characterization of the macro-environment of settlements (having a special importance for some reason) can be narrowed down to the interpretation of the micro-environment. The peripheral space zone along the wall is such a place in our immediate spatial environment.

Visual and behavioral experiences have presumably proved that the spatial relationship of base-line heterogeneous irradiation is a part of space that radiates inward and attracts people. However, the physical benefits of the environmental situation must also be taken into consideration for this experimental result. And the knowledge of this is of atavistic origin, which is much simpler to interpret than the "cave experience". We can only assume that the cave experience may have been preceded by 
the birth of some kind of "abri experience". In any case, it has a probative power for us that effectively confirms the important role this seemingly simple environmental situation plays in the formation of the structure of space.

Base-line, homogeneous irradiation. The flaring hollow-shape element formed from horizontal and vertical surfaces is the geometric definition of the simple environmental situation that has generated the spatial relationship of the base-line heterogeneous irradiation. In that case, the connection edge is horizontal. If the same surface connection is "erected" - i.e. the contact line becomes vertical - then the so-called inner corner or using a simple and sensual analogy: the corner of the room is created. Spatial boundary surfaces play the same role here, namely they function as lateral delimitation, therefore they are homogeneous elements. Thus, the initiated spatial zone created by these surfaces can be called a fundamental homogeneous conspersivity, in other words base-line, homogeneous irradiation.

The attributives base-line or fundamental mean that the properties of the inner corner can be examined close to the body, at floor level, but if the walls are high, in the upper region the spatial effect can only be experienced visually. The difference compared to the previous spatial relationship, namely heterogeneous irradiation, is that while the spatial element effect disappears at the top of the wall and under the ceiling in the first case, the homogeneous irradiation remains effective throughout the area of the vertical edge, even in the integral spatial layer.

The theoretically established assumption that the irradiating and attractive space element developed in the inner corner can be considered the second most important factor in structuring the interior space was planned to be confirmed at two experimental sites. One was the area of the already known castle wall, this time the recess formed at the junction of the protruding bastion side and the castle wall, the other was the already mentioned university hall, where this basic configuration was created using screen wall elements.

The architect students who participated in the experiment expressed their impressions as follows:

- The corner gives me a sense of security;

- I like to stay here, I find the place attractive;

- It's safe and intimate when I know the corner behind me;

- The corner reminds me of a statics exam, it's just as distressing to be in it;

- Going inside is very depressing;

- It is not good to go into it, it guides and narrows, but it can be pleasant to sit down inside;

- Approaching inwards, the sides are closing, so I feel safe, but going outside is just the other way around;

- Looking inside makes me wonder: what is this, a waterfall? Inside the corner alone is not good, but with my groupmates it is okay. Coming out of the corner, I suddenly break away from something;

- It is a pleasant, calm and friendly feeling to be in the corner; 
- The inner corner provides protection and security;

- Walking into the corner, I felt vulnerable, inside the corner the feeling of defencelessness disappeared, it was a good feeling to turn around;

- I enjoyed staying in it, it was like a pleasant interieur, in the corner I had a good conversation with my groupmates;

- I felt a pleasant protection in the nook;

- It provides protection but also restricts me;

- Definitely attracts me;

- It's more pleasant to get out of than to go in the corner. It feels good to stand with your back to the corner;

- It gives me protection, especially when I turn my back on the corner;

- The corner is depressive because I want to get adapted to it, and I can't escape anywhere;

- It feels like I'm in a room.

The effort to examine the impact of these seemingly self-evident environmental details aimed to bring to an end once and for all what scientific research has actually "gone beyond". Because the results of the experiments, which were seemingly limited to positivism and impassive fact-finding, have revealed the truth of the assumptions in a rich, colorful, and diverse way: a single empty inner corner bears many features of the interior space. These results even suggest that the forces and effects concentrated in the space corner can set up the structural framework for the "entire space".

Additional heterogeneous irradiation. Another task was to analyze the elementary spatial relationship in the area where the rising spatial boundary and the plane covering the space meet. The subject of the experiment was therefore not the interpretation of the spatial actions in the tangible layer of space, but in the layer above, in other words: at an inaccessible distance. The observation of the peripheral spatial belt of the upper-inner edge was inevitably intertwined by some interpretation of the ceiling and the interior itself.

The experimental site was a superstructure built on top of the Tabán housing estate in Buda, the surface complex of a huge water reservoir formed with retaining walls, stairs, etc. The ensemble can be accessed from the front through a fully open, covered, hall-like space, which serves as a lobby for a temporary exhibition, for observing the spatial nature of the interior. This is how the participants reported on what they had experienced in the foreground:

- The upper surface connection is strange, it closes down, I'm rounding it in my imagination;

- I don't know why, the upper-inner edge repels me, maybe if the wall and the ceiling weren't solid, but made of glass, I would feel more liberated;

- I feel good in an enclosed space when I also feel openness, so looking out of the mouth of the "cave" is better than looking inwards;

- Walking into the interior, the space did not depress me, but entwined itself around me. The sidewalls affected me more strongly than the ceiling; 
- Going towards the open side of the space, I had the impression that I was going towards the edge of the abyss;

- When viewing the side wall from about $10 \mathrm{~m}$ inside, the ceiling dominated, but when I went closer to about 4-5 m, the wall was dominant. Looking into the space, I felt the same thing: up close, the ceiling was connected to the walls, but when looking from a distance, the walls were connected to the ceiling;

- Moving inwards into the open foreground, I felt the inner space effect much deeper than the actual start of the horizontal coverage, and vice versa: when coming out I already felt outside when there was still a ceiling above me.

The definite "transfiguration" of the experimental site made the participants feel the inner space significantly more fixed than the external freedom. Among the preliminary assumptions it has been proved that the rising spatial boundaries have a stronger role in structuring the space than the ceiling, but only in situations close to the body, while looking further away - in line with the "movement" of space - the effect of the ceiling becomes stronger and determinant. It is also typical that only poor answers were given on the actual subject of the study, the spatial relationship induced by the inner-upper edge - that is about the integrative heterogeneous conspersivity. Which means that space, due to tactile and motional experiences, is more meaningful than the integral layer of space that can only be experienced visually.

Base-line homogeneous dispersion. The spatial relationship generated by the three bay-like form elements is a fundamental factor in the creation of the interior architectural space, the interieur (in other words: the inner space or the intense space). However, there are only two spatial relationships along the outer surface, generated in the area of the convex, i.e. "bodily" connection of two surfaces, along the outer corner of the house and the eaves line.

So, this is the reverse world, the external or exterieur environment, in other words, the extensive world: the public area of the streets and squares of villages, towns, and courtyards. However, there are several moments that make interior and exterior architectural spaces alike. The most important thing is that the street has sidewalks and roadway, i.e. a walking level, and the connection of this horizontal plane with the houses' sidewalls generates the same base-line heterogeneous irradiating spatial relationship as in the living rooms. This means that although the "masses" dominate the outer space, they also have a space-like image. Not to mention the gaps between the enclosed and U-shaped courtyards or the avant-corps.

However, the external nature of the space is determined by the mass-like connection of the bordering surfaces, which is the outer corner. There are two versions of this: a corner made up of surfaces serving the same purpose (e.g. the house corner) and a corner made up of different ones (the zone of the eaves, regardless of whether the roof is sloping or flat).

The first external elementary spatial relation is the base-line homogeneous dispersion, in its narrower professional name, the fundamental homogeneous dispersivity. The scene of the experiments was the corner of the aforementioned castle wall bas- 
tion, and an installation made of screen wall elements. The experimenters explained their attitudes towards the subject of the experiment as follows:

- The outer corner makes me feel insecure;

- I associate a mass with it;

- The corner of the bastion is an accentual boundary for me;

- If I have to pee, I feel like snuggling into the inner corner at the base of the bastion, why do the dogs urinate the outer corner?

- It bothers me, I feel it like a ship's bow that is heading towards me and wants to split me, I want to jump away to the right or left;

- Cold and sterile. Thoughts are swirling around in my head, it is thought-provoking. Reminiscent of an unused fireplace;

- I can only express it in one word: repelling!

- I see both sides of it, so it gives a sense of security;

- It didn't scare me, but it forces me to make a choice;

- I hate this, sword-like and sharp;

- I don't know, nothing...

- Approaching the outer corner, I wonder what comes next;

- I feel vulnerability, in other words, freedom;

- Not attractive, much more unfriendly than the inner corner;

- Good, because I can walk around, I can look back and forth;

- Standing right in front of the edge, I felt insecure, but standing a little on one side, it was already good;

- It does not provide protection, it is hard and uncomfortable;

- Good, because I can escape from here, but does not provide any intimacy;

- The outer space dominates, it is clearly an exterior space.

Theoretically, the characteristic spatial property of the outer corner zone can be determined in advance and can be described with the attributive "radiating". As before, the aim of the experiments was again to classify the seemingly obvious element of influence as a cornerstone, an axiom.

The outer corner creates two separate spatial domains, which are separated by a definite line. If I approach one side and turn at the corner, like on the axis of a scale, I will tip over to the other side, of which I have known nothing before. The space is dispersed around the outer corner. It is true that when approaching the edge I can see both sides, but only the close area of the sides can be attractive, one-by-one, not the direct foreground of the connection line. However, this is not caused by the outer corner, but by the heterogeneous irradiation generated by the ground level and the vertical spatial boundary. Consequently, the outer corner itself creates a deconcentrated and non-concentrated spatial element.

Additional heterogeneous dispersion. The elementary spatial relationship formed in the vicinity of the eaves line was examined at the Tabán water reservoir. In relation to the basic case, the question is what role the connection of the rising wall and the rearward plane (which are two surfaces behaving differently) plays in the process of 
expanding the outer space. However, the spatial relationship is two-faced, as such a bodily surface relationship can also be read from above. For example, when standing in front of the flat-roofed house I can only rely on my visual experiences, but on the flat roof I can go all the way to the edge and even sit on the edge, hanging my legs, so the object of the experiment is close to my body. At the chosen site, the experimenters commented on both variants, both from the bottom and the top of the retaining wall, as follows:

When looking up from the bottom:

- I do rock climbing in my free time, so I'm not an impassive observer: the wall is a challenge for me, I want to reach the top in order to look around there to see what is actually there;

- I squatted down at the bottom and then looked up and thought it might be good to be on top of the structure where I could breathe deeper;

- The whole thing is gloomy from a distance, but the blue sky above and behind alleviates this impression on the upper parts;

- When I stood at the foot of the wall and looked up, the wall got lower, but I still didn't know what was behind it;

- From a distance of 11-12 $\mathrm{m}$ I saw the wall as homogeneous, but from 7-8 $\mathrm{m}$ it was already divided into three parts: the lower corner, the wall and the area around the edge;

- The zone in front of the wall shrinks, opening at the top. Looking down from the top floor:

- I think it has to do with age, when I was a little boy, the edge of the roof attracted me because I was wondering what was down. Later, this feeling is tamed into a panoramic experience, everyone loves it;

- Attracted by the edge, I wonder what's down, even though I feel tension and anxiety when I go closer;

- It's two spaces: one of them covers the area of approaching the edge, and when I reach it and look down, that is the other. It's like looking out the window;

- I was attracted by curiosity, so I bravely approached the edge, then I walked along it, but then my sense of security disappeared, because from this point of view, it expresses safety, from the other side it radiates insecurity;

- I sat on the edge of the roof and the world unfolded before me.

The answers resemble the first experiment in many ways, when we examined the vertical viewing angle, together with the fundamental heterogeneous conspersivity. But this is not surprising, because the experimental situation was the same, only we did not analyze this spatial element, the integral heterogeneous dispersivity at that time, as now.

In order to achieve a full result, the above behavior of young men and women with a healthy sense of space and security should, of course, be complemented by those of other ages. But young people's opinions are also enough to determine the existence and nature of this last fundamental element of space. Like the outer corner of the mass with a vertical edge, this horizontal edge also draws a dividing line in the spa- 
tial structure: it disperses or radiates the space. Above the edge rises an invisible boundary of space, which divides the world into two parts: the known and the to be known.

\section{THREE WAYS OF SPACE CREATION}

The spatial relation that can be classified as the five axioms is created in the peripheral spatial zone. The next step in the analytical series of experiments is to determine the basic spatial perimeter forms. There are three such shapes, the circle, the polygonal and the quadrangular shape and their variants. The listed cases already represent a kind of completeness in terms of the process of flaring (widening of space), as the spatial field also emerges in and around them.

In the already well-known interior experimental site, in the hall, the different forms of space were created together, each with an own entrance. Thus, the actors were able to make comparisons by walking from one space to another.

The space-like space. The European way of thinking is rooted in the ancient Hellenic philosophy, and the approach to space in an intellectual way is also the merit of Hellenism. As already mentioned, the scholars of the science of numbers, i.e. mathematics, have discovered the spaces between the digits, and on this basis they claimed that there was the body (the soma) and the space (the topos) in which the bodies fit. Later idealistic thinking extended the factual duality of body and place (which actually means space) to the trinity of idea-space-material (ohn-chora-genesis). Finally, our issue took on a dynamic meaning when space was defined as the relationships between bodies. The space was thus derived from the system of relations of the bodies, and the organizing principle was called the taxis or thesis. And another aspect was added to all this when the theatrical scenery depicted the three dimensions in two, but with the intention of supplementing the real scene of the plot with an apparent space.

I believe that there is nothing to be ashamed of being stuck in the spatial conception of Hellenic philosophy and choose this as a starting point. We could do it boldly, because another Hellenic recognition also impressed us with its wit: the fact that the most space-like form was thought to be discovered in the circle. According to thoughts on the Hellenic circular structure, the tholos, and the prytaneion (a circular-based meeting building definitely located on the agora of Athens), the recurring arc of the circulus separates the inner world from infinite space almost imperceptibly. Here, the material-organizing principle designates a path that runs on the boundary of the bodily and the spatial. At the same time, it is also certain that for the Greeks, the circular space was originally established for community purposes.

When examining the beginnings of the human construction activity, we find that most primitive buildings of prehistoric man are embodied in organic forms, in other words: they have no corners. The shape of the dwelling pits, silos, huts, trulli, tents, yurts, etc. were all like this. These included the most abstract and purest organic shape, the circle, which ultimately has the same properties as the "cornerless" space 
enclosed by some kind of arcs. The spatial perimeter form of the circle then provided the possibility of covering the space either with straight or curved roofing, without having to raise a vertical wall. The space envelope could be developed entirely according to the same organizing principle. All this could take the form of a hemisphere placed on the ground, to which the idea of the infinite, spherical space may have been attached almost naturally.

Going even further: in ancient Eastern culture, not only the earthly world, but also its celestial parallel, the anti-world was imagined as a circle, and it was depicted on ceramic tiles accordingly. It was an indication of their view interpreting this form as cosmic and identifying it with infinite space. And the dome was considered an imitation of the sky in later historical architectures as well when it had already crowned heavy vertical side boundaries. The metropolis considered the center of the world, like the medieval Baghdad, was also surrounded by circular city walls.

Thus, it is not by chance that man felt the infinite perspectives or the "perspectivelessness" in the form of the circle (built either horizontally or vertically). And the participants of our experimental group thought similarly when observing the circular space formed from the screen wall elements, watching it either from the inside or outside:

From the inside

- I feel a complete balance;

- This space is too open for me compared to the others;

- When entering the space, instinctively, I was able to complete the spatial boundary for myself, even behind me;

- It was pleasant inside, I experienced constant evenness;

- This space is sublime and solemn, the entire rotunda is filled by warmth;

- This is definitely not a living space, but rather a community building;

- It's good to stay in and get around, because when walking along the walls I always know what's next;

- Encourages movement, it is best to walk along the wall and stop in the middle, the rest of the place is uncertain to stay in;

From the outside

- Going outside along the circular wall caused a stressful effect on me because I didn't know what was next;

- Walking around the circle was exciting because I was always curious to see what would happen next;

- Bad from the outside because it is constantly changing;

- It's a strange feeling from the outside, the arc encourages you to walk at a constant speed;

- The outer boundary of space always disappears;

- The arch carried and twisted me with itself, round and round.

The peripheral spatial belt of the circle is thus homogeneous and infinite, both inside and out, exactly because both the "inner corners" and the "outer corners" merge into one continuous line - if we think of the circle as a polygon made up of 
an infinite number of tiny sides, as it is. And the spatial field can be considered intensely (internally) a single, self-recurring, inwardly radiating inner "corner", while extensively (externally), a dispersing outer "corner". The change of direction of the delimiting surface obviously and discreetly turns into infinity, so a kind of spatial harmony characterizes both the peripheral spatial belts and the spatial fields. The same can be said not only for this regular shape, but also for all kinds of spaces encircled by curved spatial boundaries, because the material that brought the space to life is itself shaped in an airy way. Invisible architecture can be created with the help of curved boundary surfaces.

The sectioned space. Regular polygonal spaces form a transition between circular and rectangular cornered spaces. For in both, the boundary of space forms a unity by moving symmetrically in all directions relative to the central axis. The difference is that the change of direction of the surface running at the boundary of a regular polygon takes place in sections, in slight fractures, while in the case of a circle the space boundary is unbroken.

The centrality of these spaces caused the experimenters to discover many similarities between a regular polygonal and a circular floor plan space. They did not consider it to be an everyday form either (i.e. suitable for living), they also felt a certain theatricality in it.

The participants felt the interior "open" relative to the rectangular space with corners. Despite the broken line of the wall, the spatial effect was not judged to be fixed and rigid, but pleasant, safe, and balanced. The polygon reminded them of the circle from the outside, but they noted that while the boundary surface continuously "disappeared" during the walk around the circle, in the case of the polygon many short, straight sections followed one another, suggesting what was to come.

While searching for the origin and genesis of the basic spatial perimeter forms, we came to the conclusion that the first polygonal space in the history of Western architecture was, to the best of our knowledge, Adronikos' clockhouse, the Tower of the Winds in Athens. The shape of the octagonal structure built in $50 \mathrm{BC}$ is thus the youngest space formation in chronological order, since man had built spaces with a circular, square and rectangular floor plan thousands of years before. The reason for the floor plan of the small meteorological observatory is well known: it became octagonal because it marked the eight directions of the compass rose, according to the testimony of the wind gods depicted in person on the frieze, and the weather vane rotating on top of the edifice. The circle was thus divided into intermittent sides, and the building was placed in the middle of the supposed "rose" of directions and radius of the surrounding spatial world.

In the case of Domus Aurea, the palace of Nero in Rome, which was built a hundred years later, the emperor's biographer called the octagon the copy of the universe. Also, other regular polygonal, pentagonal, hexagonal, decagonal, etc. spatial boundary forms carried symbolic meanings. The space, surrounded by uniformly sectioned spatial boundaries, was thus an invented "artificial form" (this is the reason why it 
has emerged so late) and was indeed applied to purposes that required great care ${ }^{3}$. Irregular polygonal spaces are only numerically related to polygons, so irregular ones can be interpreted as inorganic cornered spaces.

The interruption of the spatial boundary surface (i.e. the entrance to the space) has an obvious effect on the space structure, because it really matters how many openings there are and where the so-called space starts open. The experimental situations were wittingly provided with only one entrance, to enable the analyzation of the different forms of spatial boundaries in their own integrity.

In the case of a circle and a regular polygon, it is completely indifferent where the single entrance is opened. The result is the same for both: standing in the door, the space is fully revealed, but the vertical axis formed in the center is intersected by a horizontal axis, which designates the further division of the space and determines its arrangement. The purity of the centrality of the rotunda can only be maintained if it was possible to enter the space in the center, coming out from under the floor. Or more entrances are needed: three or even four doors on the main axes. So, for the first time in history, Palladio created a true central circular space.

As for a cornered space, it is a thought-provoking fact that the origin of the rectangular spatial shape and its spread in architecture is obscured, and science fails to give a clear explanation of its formation to this day. Yet we live in such rooms day by day, and it can be stated even without accurate statistics that rectangular spaces are the most common in the global architecture.

Who believe in the controlling power of the material and technical aspects of architecture, primarily think of wood as a construction material. In ancient times, among the natural building materials, earth, clay, and unprocessed stone blocks were mostly suitable for the construction of the "shapeless", i.e. organically shaped structures. In the form of some creatures of the flora, like sedges, reeds, and straightstemmed trees, there was the possibility of assembling some kind of cornered structure. And when people switched from the timber construction to the use of bricks (as can be observed in the prehistoric architecture of Mesopotamia), the so-called plano-convex bricks were mostly used to build curved wall structures, but rectangular houses were also built from square bricks. Some researchers have deduced the origins of the rectangular forming method from the weaving technique, the system of wraps and wefts.

From an architectural point of view, it would be unprofessional to ignore such phenomena. However, in addition to the dominant influence of the material, something else would be needed for the form element to become general. And here we can rightly refer to the verticality of the human physique, our right and left hands, the primarily horizontal nature of our field of vision, and the primary and involuntary forward direction of our movement. If the assumption that man projects this coordinate system onto his environment is true, then it automatically follows that the right angle, either way, is a human geometric shape. When we admire the beautiful shapes

\footnotetext{
${ }^{3}$ In Hungarian "artistic care", the etymon of which is identical with that of the word "artificial".
} 
of ice crystals, the process of crystallization, the texture of the cell system of the hive, microscopic sections of living tissues or even cloud clumps, the bizarre beauties of mountain ranges, etc. geometry and organicity can be found everywhere in nature, but almost nowhere is the "simplest" geometric shape, the right angle. Cubism provoked some resentment in the vast majority of people living in the last third of the $20^{\text {th }}$ century, because they felt it inhuman and they compared the housing estates of this style to necropolises. But the question rightly arises: what kind of being of the Creator can conjure a cube-like mass (in our example this means a flat-roofed house) on the soft-lined, sloping-leafy hillside? Only the man.

At the heart of the phenomenon is probably the fact that man created an order around himself according to the coordinate system inherent in himself. On the cross, on one side of the Savior hung the good criminal, on the other the bad. Up there, Heaven awaits the one who lived honestly, but people who lived dishonestly must descend into hell. To explain the cardinal directions to young children, we often tell them the (Hungarian) rhyme: "Elöttem van észak, hátam mögött dél, balra a nap nyugszik, jobbra pedig kél”, meaning: In front of me is north, behind me is south, the sun rests on the left, and the sun rises on the right. The Roman augurs drew a cross to the sky and performed augury based on the number of birds flying into the four parts, and on the direction of their flight. This cross (projected on the ground) became the so-called temple, the frame for the four-region cities, the Roma quadrata, and all Roman-based settlements, military camps, and civilian cities, and it also marked the right angles of the two main roads, the cardo and the decumanus.

The right angle means a man-made order. When mentioning the Roman city, the other (earlier) classical culture, the Hellenistic urban pattern should be considered too, namely the siting according to an orthogonal grid of streets. Aristotle writes the following about this: "The arrangement of the private dwellings is thought to be more agreeable and more convenient for general purposes if they are laid out in straight streets, after the modern fashion, that is, the one introduced by Hippodamus; but it is more suitable for security in war if it is on the contrary plan, as cities used to be in ancient times; for that arrangement is difficult for foreign troops to enter and to find their way about in when attacking. Hence it is well to combine the advantages of both plans (for this is possible if the houses are laid out in the way which among the farmers some people call 'on the slant' in the case of vines), and not to lay out the whole city in straight streets, but only certain parts and districts, for in this way it will combine security with beauty." In other words: if we could count on permanent peaceful conditions and not have to fear the chaos caused by the enemy, then the whole city could have the so-called regular settlement structure, i.e. a "normal" grid at right angles. However, it is another question (but also part of the dialectic of architecture) that for Aristotle, the organic form means security, that is, a kind of necessary utility, and the regular form means beauty - while most people today do not think so.

Experimental testing of the rectangular spatial perimeter form required more complex sequences of actions than the previous ones, which may sound surprising as it 
appears to be the most common and general form. Rectangular cornered space has much more variations than the circular or regular polygonal floor plans. It can be a square or can be formed according to the variants of the oblong: from a long corridor through the balanced-proportion rectangles to the spacious halls. And the purposeful constraint of opening only one entrance to the space showed that the spatial structure of the same rectangular room changes completely when the entrance is placed on different sides. All these necessitated the conduction of some introductory and additional experiments.

The experimenters commented on the situation of the acute angled spatial boundary relationship and the triangular spatial perimeter form as follows:

- The spatial effect of the acute-angled inner corner is narrow and depressing;

- It didn't evoke a sense of space in me, I just see a screen;

- Tight feeling, worst of all of the inner corners;

- It's nice enough inside, if I face outside;

- I felt in a mad-house, where I was sitting in the corner as a patient just entertaining myself;

- It still feels better than the stiffness of a right-angle corner.

As an evaluation, it can be stated that the "stubbornness", if you like: aggressiveness of the narrow space was a characteristic opinion. The attraction of the flaring spatial relationship appears again, but only with one's back to the corner, and the reaction of the experimenter waiting for strong impressions, i.e. preferring the unusual is interesting.

In the case of an equilateral triangular spatial perimeter form prepared as a further "preliminary study" of the rectangular space, the entrance was opened first in the middle of one side and for the second time at the corner of one.

In case of a side entrance:

- My first impression was determined by the corner opposite me, which was quite uncomfortable. Turning in the corner, I felt symmetry for a moment, but the space was not pleasant;

- I entered, the opposite corner sucked me in, then I turned and felt insecure;

- It's best to stay in the middle;

- I wasn't attracted to the corners, I felt most comfortable in the center;

- When I went in alone, it wasn't good, it was better to be inside with a group;

- When we entered the space in groups, I didn't feel it as "wild" as alone, because then - with a company - the spatial effect was "tamed".

The equilateral triangular space is actually central, and this has been perceived by some participants. The case study also provided an example of how the effects of a temporary (ephemeral) and a permanent (chronic) space are layered. Namely, it turned out that the given spatial shape was suitable for gathering, but here with such a "background feeling" that the effect, originally judged to be too rough, was gradually softened during the group stay. 
In the case of a corner entrance:

- The corner entrance is more pleasant than the side opening, because the space does not narrow suddenly, but when coming out, you almost have to sneak out the door;

- Entering the side entrance, the opposite corner marked a destination, but now entering on the corner, I didn't know if to go right or left;

- I didn't feel like going in because when I stopped at the entrance, I saw the whole space;

- The corner entrance version is significantly better than the side door, but this space is not good in any way;

- This space is like the deceptive street girl who shows her most beautiful side. The space sucked me in, then I looked back and forth in the corner, which was uncomfortable, but when I turned around, the room pushed me out. Enjoyable for a short time, but not for longer stays...

Undoubtedly, there are spatial densities in the few but narrow corners of the triangular space. Three definite, evenly spaced poles are formed in the peripheral spatial belt, thus creating a somewhat balanced spatial field. Nevertheless, in this type of space (quite rarely used in practice) the spatial stresses are high.

In experiencing the "behavior" of angularity, the next experimental situation was represented by a square space with a corner entrance. So, this was the situation in which the spatial boundaries were connected at right angles but did not give that feeling. This time, the opinions of the young to-be architects were as follows:

- This approach is not disturbing, it is nice that I do not see fixed, hidden places and I see the whole space;

- This space is cozy, slowly introduced, I looked around like in the woods, where man just contemplates the trees. It was not the space that dominated, I had the feeling that I was in control;

- I likened it to a circle in my mind, I went around, I beveled the corner, as I always do;

- It looks like a triangular space, the corner opposite the entrance attracted me, when I turned my back here, the space unfolded;

- I immediately started to walk along the diagonal, stopped in the middle of the space, it was pleasant there. It is true that the triangular space came to my mind, but the feeling of being closed was not distressing here.

Unconventionally entering the "equilateral rectangle", i.e. the quadrat evoked a sense of centrality in several visitors. There were those who softened the corners in their mind and felt best in the middle. Of course, reference was also made to the triangle. Either way, there is no doubt that the spatial relationships of the corners have a decisive influence on the formation of the spatial structure.

Finally, the approach to the actual experimental space followed, that of the rectangular spatial form that fits latently into the spatial order inherent in man. As a first step, the experimental situation was designed so that the entrance to the square space was opened in the middle of one side. A specific comment of the general remarks 
says that this is the only spatial form that is "the same" from the inside and outside. From the outside, because you can prepare for a change in the direction of the spatial boundary.

This is how the specific answers came one after the other:

- It is the usual form of space since I have lived in this for nineteen years. Is this the square? I didn't even notice, but it doesn't matter. Whether quadrat or oblong, the point is that it is rectangular;

- I went in alone, this space has a pleasant, homely shape;

- I walked around alone, avoiding the corners;

- It is better to be inside in a group. Space, as a concept, didn't even occur to me, we just had a good time together. When I was alone inside, the walls irritated me, and it was only good to look at the entrance;

- Going inside alone, I would guess that I should perform something while standing by the wall, I felt calm in the corner opposite the entrance. These are kind of waiting places, but staying in the corners next to the entrance makes me feel so lurking or searching;

- It is a "normal" space, some furniture is missing...

In the responses given, the nature of the spatial structure unfolds in a colorful way, and with great variety. The sterile imagined inward radiation of the inner corner - because of its attractive effect and impact on our staying - takes on different meanings due to the position of the corner and its relation to the entrance. But the observations are common in saying that tension and polarization are created in space. And the experimental situation refers to all three aspects of human space: the relationship between the temporary, ephemeral space (coming from the group situation), the solidly formed, chronic space, as well as the need for installed space. It is no coincidence that during the series of experiments, the idea of furnishing the space first appeared here, seeing the room in the shape of a rectangular perimeter. It is a cliche that these standard spaces can be furnished for everyday use (with beds, cabinets, tables, etc.) with the most economical use of space. The only question is whether the rectangular shape of the space is common and familiar just because a teenager felt the need to put something in or is it a general living space formula suitable for human habitation. Assumptions and experience suggest that the roots go deeper: beneath the ground of habit and innervation.

The series of experiments ended with an impact assessment of the 1:2 scale rectangular floor plan. To observe the human behavior in a truly standard, oblong spatial perimeter form of balanced proportions, the participants gathered inside the space and a single screen wall element symbolizing the door was put in place, so the space became doorless (closed). According to the action situation, one participant read poems to the others. The question was: how the group members could find their place. Well, the students sat down along the longitudinal axis, forming a mass roughly like the space, and were listening to the declamation of their peer standing by the shorter wall. In fact, the need for a detailed experiment would have required this 


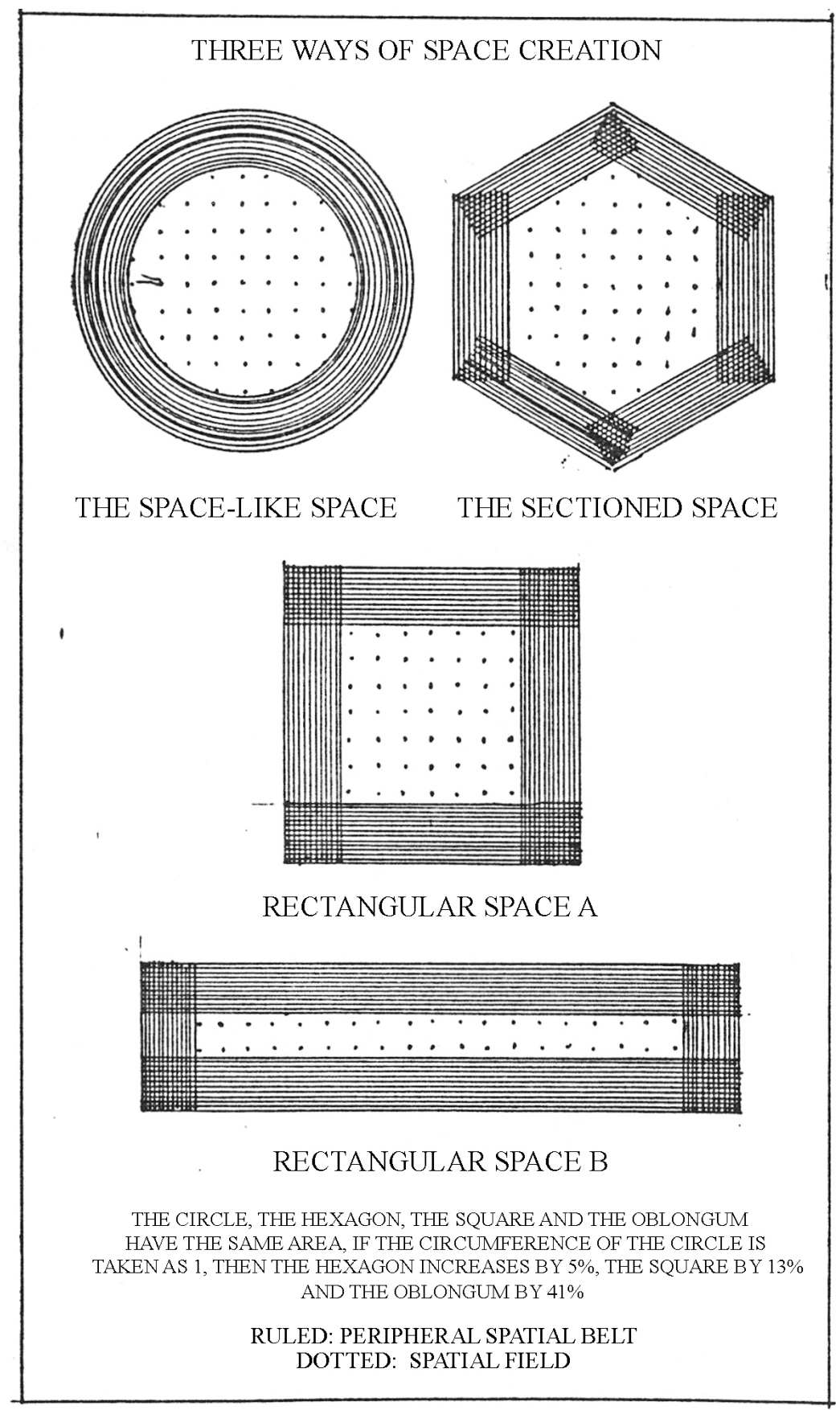

Figure 5. Three ways of space creation 
closed situation to be analyzed for each spatial form - even if it is actually an absurd situation - because in this way their spatial effect could be assessed "cleanly".

First, the entrance panel was left out on the shorter side of the same spatial form, and for the second time, in the middle of the longer side, so the experimenters have "faced" a space with a longitudinal or a cross "nave". They said, the longhouse layout led through the space, they felt it corridor-like and encouraging the movement along the central axis. Another participant thought that the side walls dominated, but he was also attracted by the sight of the narrow closing wall. Again, others were disturbed by the constraint because their movements had no alternatives. The following were said about the experiences of the cross-nave space: it presents a dilemma, the big wall is in front of me, I cannot go to it, but then where to go? This space does not even have a side wall, said the other participant. Two poles are formed: this way and that way.

We finally opened the entrance to the rectangular space where the end of the longitudinal side joins the shorter boundary wall, so not specifically in the corner, both with right-hand and left-hand swing, one after the other. Thus, a so-called elbow-joint-axis spatial structure was created. The actors, almost without exception, headed for the larger space, and the area of the corner opposite the entrance was almost unnoticed. The eccentric entrance thus forced visitors to change their course in one direction. The right-handers thought it was more pleasant to be able to start to the right when entering.

In summary, it can be stated about the cornered spaces that the process of spatial formation does not take place unnoticed, but it is the result of clearly distinguishable elements of influence overlapping and interacting with each other. Cornered spaces are therefore called indiscreet spaces.

The elements of influence are stronger in the corners of the space than along the unbroken boundaries of the space, therefore the spatial tension is generated according to the distance between the corners. It also varies according to the type of corner connections, as in trapezoidal or irregular rectangular spaces, spatial elements of different intensities are formed in the corners. The nature of the peripheral spatial belt formed by the shape of the space boundary is then modified by the location and number of the entrance(s). Different space starting elements cause balance (symmetry) or tilt (asymmetry) in the spatial field, so tensions also arise here. Thus, the name polarized space expresses the point: these are polarized rooms in several ways (Fig. 5).

\section{THE EVOLUTION OF ARCHITECTURAL SPACE}

The space types mentioned with the collective name "spatial", "segmented" and "cornered" developed from the spatial perimeter form and represent the intermediate phase of the process of space creation, as they do not include the power of topping the space yet. However, the importance of the spatial perimeter form is further 
enhanced by the simple geometric fact that the delimitation of the same floor area requires different length of boundary walls for each basic type. The circular wall is the shortest, the circumference of the polygon is slightly longer, while in the case of a square the difference is perceptible, and for a stretched rectangle the boundary wall length increases quite significantly. Which means that the proportions of the peripheral spatial belt and the spatial field also change significantly, both in terms of form and quantity. In fact, less material is needed to create a space-like area, so they are 'more airy' and the spatial field is the dominant there, while the construction of the other extreme, i.e. the oblong space requires much more material, and here the peripheral spatial belt is the determinant factor.

The further course of the process of spatial formation - the development, evolution and completion of space - is not discussed in this paper. We only give an outline of what follows.

The morphological reality of the entire enclosure needs to be elaborated in more detail. After all, this study was just about the basic types. Variants of these, the different approaches, the articulation of the delimiting surfaces, the many variations of the spatial separation are theoretically elaborated, but they are waiting for experimental confirmation. Topping the space from above further complicates the issue, because the roofing can harmonize with the shape of the spatial perimeter (hemispherical domed rotunda, polygon with ribbed dome, oblong rectangle with flat ceiling), but it can also be of a different nature (circular space with flat roof, square covered with a ribbed dome, or a rectangular space with vault). And the multitude of other spaces and their modes of spatial connection complete all this. And the chronic, timeless space is just the frame and opportunity of our lives. Even if the assumption is true that many human thoughts, gestures, and behavioral elements have already manifested in these spaces, they are still made alive by those who live in them, who inhabit, furnish, and use these spaces. Only the exploration and nuanced interpretation of the "secrets" of the installed and ephemeral space makes the chronic (architecturally shaped) space real.

\section{REFERENCES}

(1) Ankerl, Géza: Épitészet és kommunikáció. [Architecture and communication] Müszaki Könyvkiadó, Budapest 1991.

(2) Hajnóczi, J. Gyula: Vallum és intervallum. Az épitészeti tér analitikus elmélete. [Vallum and intervallum. Analytical theory of architectural space] Akadémiai Kiadó, Budapest 1992.

(3) Lavas, Georg: Die griechischen Thols-Bauten der klassischen Zeit und die Wandlung der architektonischen Raumgestaltung. Thessaloniki 1974.

(4) Muck, Herbert: Der Raum. Baugefüge, Bild und Lebenswelt. Akademie der Bildenden Künste, Wien 1968.

(5) Hempel, Helmut: Raumspielmodelle von Herbert Muck, als semiotische Aktionsexperimente. Wien 1979. 


\section{AZ ÉPÍTÉSZETI TÉR GENEZISE}

\section{Összefoglaló}

Az itt közreadott tanulmány első változata magyar nyelven íródott, az „Épület- és településkarakterológia” címü OTKA-kutatás zárótanulmányaként. ${ }^{4}$ „Az építészeti tér genezise” címủ tanulmány Hajnóczi Gyula térelméleti kutatásainak tömör, de az építészetelméletben kevésbé jártas kutató számára is alapvető áttekintést adó összegzése. Az értékes írást - jóllehet magyarul folyóiratcikk-sorozatként, illetve sokszorosított formában is megjelent - az építész szakma alig ismeri. ${ }^{5} \mathrm{Az}$ itt közölt, angol nyelvre fordított változat egyrészt Hajnóczi térelméletének szélesebb körü megismerhetőségét segíti a szakmai körök számára, másrészt az angol nyelven tanuló diákság számára is fontos olvasmányként szolgálhat. A fordítás az OTKA-zárótanulmány későbbi, folyóiratba szánt változata szerint készült el, a jogutód támogatásával. ${ }^{6}$

Kulcsszavak: építészetelmélet, térelmélet, téralkotás

${ }^{4}$ „Épület- és Településkarakterológia” című 283. számú OTKA-kutatás, 1988-1991; témavezető: Hajnóczi Gyula.

${ }^{5}$ Építész folyóirat nem közölte, nyomtatásban az oktatással-neveléssel kapcsolatos kutatásokat közlö Iskolakultúra címü lapban jelent meg. http://www.iskolakultura.hu/index.php/iskolakultura/ (Utolsó megtekintés: 2020. 12. 15.): Hajnóczi J. Gyula: Az építészeti tér genezise. I. Iskolakultúra 2 (1992) 22. 2-10. http://www. iskolakultura.hu/index.php/iskolakultura/article/view/28788; Hajnóczi J. Gyula: Az építészeti tér genezise II. Az érzékszervek szerepe a térérzékelésben. Iskolakultúra 2 (1992) 23-24. 10-21. http://www.iskolakultura.hu/ index.php/iskolakultura/article/view/28809; Hajnóczi J. Gyula: Az építészeti tér genezise III. Az építészeti tér megteremtése. Iskolakultúra 3 (1993) 1. 20-33. http://www.iskolakultura.hu/index.php/iskolakultura/article/ view/28846; Hajnóczi J. Gyula: Az építészeti tér genezise IV. Iskolakultúra 3 (1993) 5. 35-43. http://www. iskolakultura.hu/index.php/iskolakultura/article/view/28918

${ }^{6}$ A zárótanulmány javított szövegverziója az Iskolakultúra említett számaiban jelent meg magyarul, az itt közölt fordítás Gaschler-Gyeviki Nóra munkája.

$\leftrightarrow$ Received: 21 October 2020. Accepted: 22 October 2020

First published online: 6 March 2021 